\title{
Biodiversity of laccase producing fungi in Egypt
}

\section{Abdel-Azeem AM ${ }^{1 *}$ and Salem FM}

${ }^{1}$ Laboratory of Systematic Mycology, Botany Department, Faculty of Science, University of Suez Canal, Ismailia 41522, Egypt.

Abdel-Azeem AM, Salem Fatma M 2012 - Biodiversity of laccase producing fungi in Egypt. Mycosphere 3(5), 900-920, Doi 10.5943 /mycosphere/3/6/4

Laccase enzyme (EC 1.10.3.2) is a benzenediol, a multi-copper enzyme, and one of the three main ligninases that differs from the others in its ability to catalyze the oxidation of lignin components. It is widely distributed in fungi and because of its importance in bioremediation; the search for fungal laccases with different properties and potential applications is still on-going. In view of its importance in large scale application, the present endeavor is to search for highly efficient laccase producing fungi from different environmental habitats in Egypt. Cultural conditions such as temperatures, $\mathrm{pH}$, carbon sources and nitrogen sources were optimized for the production of high extracellular laccase activity. By screening sources under investigation namely: soil, wood, seaweeds, sponge, ascidia, drifted decaying wood, plants and miscellaneous materials it was possible to encounter as many as 60 species belonging to 33 genera. Zygomycota represented by six species (10.16\% of the total species number), teleomorphic Ascomycota (9 species, 15.25\%), anamorphic Ascomycota (44 species, 74.57\%) and Basidiomycota (1 species, 1.69\%). Soil showed the highest Simpson's species diversity index of 0.83 while contaminated wax samples and Adiantum capillus-veneris showed the lowest value (0). All isolated taxa were tested for laccase production using a qualitative plate assay method by using guaiacol as color indicator. Sixteen isolates showed positive reaction indicating a lignin-degrading potentiality and out of them eight measured the highest zone diameter with high oxidation scale. The most promising taxa were endophytic namely: Chaetomium globosum, Phoma exigua, Thanatephorus cucumeris and Sordaria

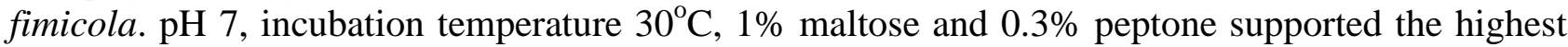
biomass and laccase production for Chaetomium globosum.

Key words - ascidia - Chaetomium globosum - entophyte - seaweeds - sponge - wood

\section{Article Information}

Received 8 September 2012

Accepted 30 October 2012

Published online 15 November 2012

*Corresponding author: Ahmed M. Abdel-Azeem - e-mail - zemo3000@yahoo.com, ahmed_abdelazeem@science.suez.edu.eg

\section{Introduction}

Laccase, as a large blue coppercontaining protein, is widely distributed in a wide range of living organisms e.g. higher plants and fungi (Leontievsky et al. 1997, Mendoza 2011), insects (Hattori et al. 2005) and bacteria (Claus 2004). Recently, a novel polyphenol oxidase with laccase-like activity was mined from a metagenome expression library from bovine rumen microflora (Beloqui et al. 2006). In 1883 Yoshida extracted and described laccase for the first time from the exudates of Rhus vernicifera (Japanese lacquer tree). In 1895 Bertrand demonstrated the presence of laccase in fungi for the first time. Over 60 fungal strains belonging to the phyla 
Ascomycota, Zygomycota and Basidiomycota, particularly many white-rot taxa show laccase activity (Baldrian 2006).

Due to their higher redox potential, fungal laccases are used in many biotechnological important applications especially in the degradation of lignin and elimination of potentially toxic phenols arising during lignin degradation. One of the most important enzymes in the biopolpation process in pulp and paper industry are laccases which have the ability to depolymerize lignin and delignify wood pulps, kraft pulp fibers and chlorine-free (Bourbonnais et al. 1997, Lund \& Ragauskas 2001, Chandra \& Ragauskas 2002, Camarero et al. 2004, Rodríguez \& Toca 2006, Vikineswary et al. 2006).

Fungal laccases also play an important role in physiological processes related to pathogenesis (Edens et al. 1999), morphogenesis i.e. fruiting body development (Kues \& Liu 2000, Ohga \& Royse 2001), pigmentation (Eggert et al. 1995) and cell detoxification (Bollag et al. 1988). Laccases from fungi have been used in food and beverage industry enhancement or modification (Ghindilis 2000, Minussi et al. 2002, Rodríguez \& Toca 2006, Selinheimo et al. 2006, Minussi et al. 2007). Laccases are involved in green biodegradation of xenobiotic contaminants in soil (Rodríguez \& Toca 2006) and polycyclic aromatic hydrocarbons (Anastasi et al. 2009). Laccases-mediator systems are powerful tools in dye processes and textile industries (Kunamneni et al. 2008). Laccases are also used as catalysts for the manufacture of anti-cancer drugs, in the cosmetic industry and have also been applied to nanobiotechnology (Xu 2005, Rodríguez \& Toca 2006, Ponzoni et al. 2007, Kunamneni et al. 2008, Mikolasch \& Schauer 2009).

In Egypt fungi producing laccases attracted the attention of various investigators by the late 1990s. Laccase activities produced by different ecological groups of Egyptian fungi have been the subject of many studies carried by Abdel-Raheem (1997), Yehia (2007), EL-Zayat (2008), Youssef et al. (2008) and Atalla et al. (2010). Other investigators studied the various applications of laccases in industry and medicine such as El Fallal (2001), Gomaa (2005), El-Fallal \& El-Diasty (2006),
Abd El-Thalouth et al. (2008), Abedin (2008), Gomaa et al. (2008), El-Fakharany et al. (2010), Abd El-Rahim \& Moawad (2010), Abou-Okeil et al. (2010) and Gomaa et al. (2011). Molecular studies on characterization and cloning of laccases genes were carried by other Egyptian researchers viz. El-Shora et al. (2008) and Moussa $(2009,2011)$.

It is estimated that there are approximately 1.5 million fungi species in the world, of which around $4.6 \%$ are known (Hawksworth 2001). The Egyptian fungi are presently represented by 2281 taxa $(1,035$ species and 395 genera) out of the 101,202 world records (Abdel-Azeem 2010). The potential fungal resources of Egypt are globally important and vast areas are still unexplored. The extensive collection of fungi in unexplored areas remains a research priority (AbdelAzeem 2010).

Marine-derived fungi represent a rich source of bioactive metabolites, especially enzymes, which have not yet been fully exploited in Egypt and have never been the target of any solid study before. Based on the aforementioned, the objective of the present work was to study the biodiversity of laccase producing fungi in Egypt through isolation, identification and qualitative assessment of laccase from different ecological habitats with special reference to marine habitat. In addition this study aims at optimizing cultural conditions supporting high biomass and laccase yield from a local isolate to enable the selection of such fungi with the greatest biotechnological potential.

\section{Methods}

Sampling - A range of terrestrial samples (soil, plants, and wood), marine (seaweeds, sponge, ascidia, and submerged decaying drifted wood), contaminated wax and water colour samples were screened in order to give a preliminary view of laccase producing mycobiota of Egypt.

One hundred rhizospheric soil samples were collected from the dominant plant species (31 plant species) between July 2010 and October 2010 from 20 different sites throughout different elevation wadis (Table 1) in Saint Katherine Protectorate. These were placed in sterilized polyethylene bags, closed 
Table 1 Location of soil sampling sites and dominant vegetation

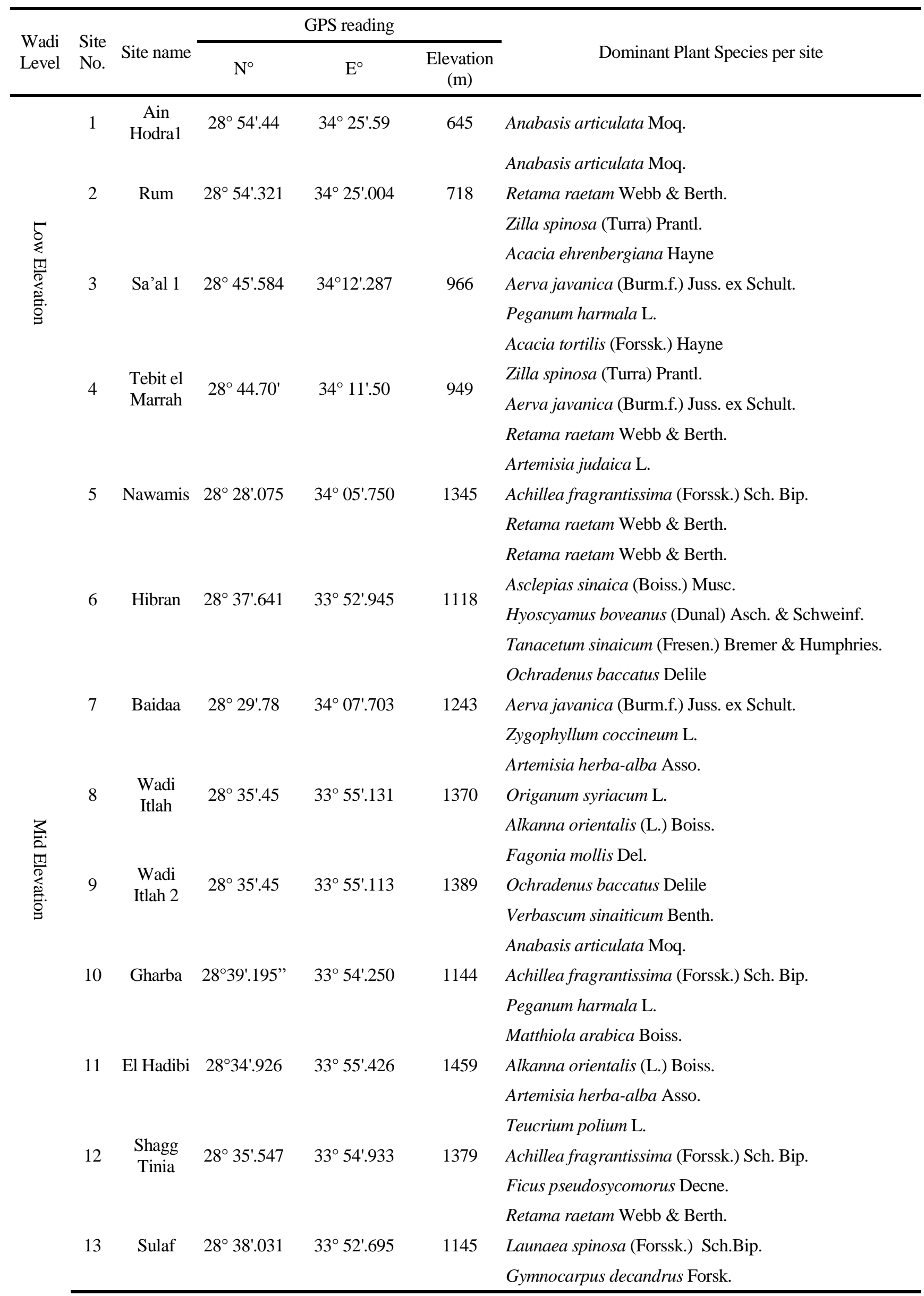




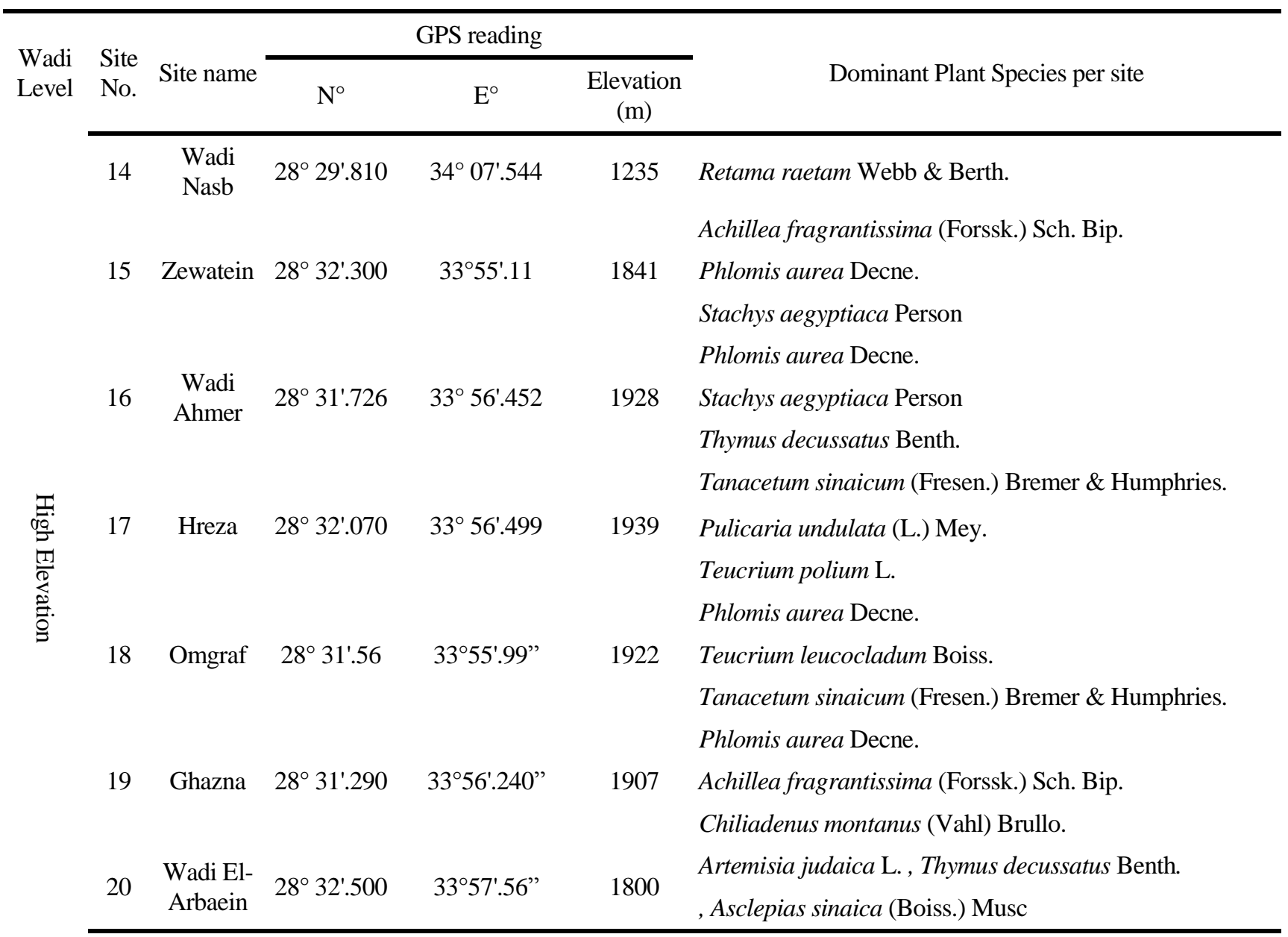

soil samples were collected and mixed thoroughly to form one composite sample. by rubber band, and transferred to the laboratory until plated out. From each site, five samples were collected from each non terricolous substrate. Adiantum capillus-veneris L., Phlomis aurea Decne. and Alkanna orientalis (L.) Boiss. were collected from Wadi ElTalaah, Saint Katherine Protectorate, South Sinai for isolation of associated endophytic fungi. Wood samples of Acacia tortilis subsp. raddiana Savi and Ceratonia siliqua L. were collected from Wadi Feran and Wadi Itlah, South Sinai.

Six species of dried seaweeds collected from Suez Canal namely: Ulva lactuca L., Caulerpa serrulata (Forssåk.) Agardh and $C$. prolifera (Forssk.) Lamouroux from green algae, Hypnea cornuta (Kützing) Agardh and Sarconema filiforme (Sonder) Kylin from red algae and Cystoseira myrica (Gmelin) Agardh from brown algae.

Specimens of the sponge (Hippospongia communis) were collected from the western region of the Mediterranean Sea (El-Hamam, Sidi Abd-El-Rahman, Alam El-
Room, Matrouh and Barrani). Ascidian samples belonging to Phallusia nigra Savigny, Micsocosmus pupa Savigny, Styela plicata Lesuer and Polyclinum constellatum Savigny were collected from Suez Canal.

Submerged decaying drift wood were collected from Mediterranean Sea coast at Port Said, El-Arish and Suez. Also contaminated samples of wax and water colours were collected from Port Said Governorate. The samples were transferred to the laboratory in an ice box for further study.

Isolation, maintaining and laccase screening media- The isolation and culture maintaining media for marine taxa were prepared with sea water (SW) and supplemented with Rose bengal $(1 / 15,000)$ and chloramphenicol $(50 \mathrm{ppm})$ for suppression of bacterial growth. Five media were adopted for isolation after Atlas (2004); these were: sea water rose Bengal chloramphenicol agar (SWRCA), sea water Czapek's yeast extract agar (SWCYA), sea water oatmeal agar (SWOA), sea water agar (SWA), and sea water potato dextrose agar (SWPDA). 
The same media with distilled water were used for isolation from soil, plants and contaminated samples. For maintaining and identification of the isolated fungi, media such as vegetable agar (V8), oatmeal agar (OA), malt extract agar (MEA), potato dextrose agar (PDA) and potato carrot agar (PCA) were used.

Two screening media were used for qualitative assay of laccase: guaiacol supplemented agar (D'Souza et al. 2006a) and modified Czapek's agar supplemented with $0.02 \%$ guaiacol (Viswanath et al. 2008). The media were supplemented with sea water (50\%) for marine organisms and distilled water for terrestrial taxa.

Isolation - A total of 1000 plates from 40 different environmental samples previously listed were used for isolation of mycobiota. Mycobiota of soil and contaminated samples were isolated using a dilution plate method (Garrett 1981). Pieces $\left(5 \mathrm{~mm}^{2}, 4\right.$ pieces in each plate) of stem, root and wood from different plant species, Adiantum capillus-veneris, Phlomis aurea, Alkanna orientalis, Acacia tortilis and Ceratonia siliqua were surface sterilized (Fisher et al. 1993) and cut for isolation of endophytic fungi. The samples were washed in running water, immersed in $70 \%$ ethanol for $1-5 \mathrm{~min}$. according to the thickness, dipped in 5\% NaOCI for 3-5 min. and then in $70 \%$ ethanol for 30 seconds. The sterilized samples were plated on appropriate isolation media.

Seaweed samples were washed thoroughly in sea water and rinsed 3 times with sterile sea water (SSW). Samples were aseptically sliced into small pieces $\left(5-10 \mathrm{~mm}^{2}\right)$ and placed in sodium hypochlorite solution (5 $\%$ ) for 1 to 2 min according to the thickness of each algae, rinsed 3 times with SSW, immersed in ethanol $(70 \%)$ for $2 \mathrm{~min}$, rinsed several times with SSW and placed on different isolation media. Algicolous fungi were isolated by grinding $5 \mathrm{~g}$ (fresh weight) of each sample which was previously surface sterilized, as mentioned before, in a sterile mortar with 50 $\mathrm{ml}$ of SSW, homogenized with pestle and then $1 \mathrm{ml}$ of liquid portion placed on agar plate of different isolation media.

To get rid of non-specific fungal propagules from seawater column on sponge surfaces, animal tissues were rinsed three times with sterile seawater. The surface of the sample was disinfected with ethanol $(70 \%)$ for 2 minutes. The inner tissue was taken out with a scalpel and forceps and then cut into small cubes $\left(\sim 5 \mathrm{~mm}^{3}\right)$. A total of 15-20 cubes of each sample were placed on isolation media.

Ascidia tissues were rinsed three times with sterile seawater in order to get rid of any microbial contamination from seawater, rinsed in ethanol (70\%) for 2 minutes, re-rinsed with SSW several times, dissected into pieces (5-10 $\mathrm{mm}^{3}$ ) and then placed on different isolation media.

Fungi from submerged drift wood were isolated by direct isolation technique after washing the samples with sterile sea water, incubated in plastic boxes lined with wet tissue at room temperature and examined periodically over 3 months.

Identification of isolates - Taxonomic identification using morphology characteristics of fungal isolates down to the species level, on standard media, was mainly based on the following identification keys: Raper \& Thom (1949), Pitt (1980) for Penicillium (on Czapek's yeast extract agar (CYA) \& malt extract agar (MEA)); Raper \& Fennell (1965) for Aspergillus (on Czapek's agar (CZ)); Ellis (1971, 1976) for dematiaceous hyphomycetes (potato carrot agar (PCA)); Booth (1971) for Fusarium (potato sucrose agar (PSA)); Arx (1981), Domsch et al. (2007), Watanabe (2002) for miscellaneous fungi (on MEA, PDA, CYA); Arx et al. (1986) and Cannon (1986) for Chaetomium (oat meal agar + lupin stem (OA+LUP)). The systematic arrangement follows the system of classification appearing in the $10^{\text {th }}$ edition of Ainsworth and Bisby's Dictionary of the fungi (Kirk et al. 2008) and Species Fungorum (http://www.speciesfungorum.org/Names/Nam es.asp).

Qualitative assay of laccase - For examination of laccase production, $5 \mathrm{~mm}$ diameter discs from 7 days old colonies were placed on the surface of guaiacol supplemented agar plates (D'Souza et al. 2006a) and direct inoculation into modified Czapek's agar plates and incubated at $25^{\circ} \mathrm{C}$ in dark for 7 days. The production of intense brown colour under and around the fungal colony was considered as a positive reaction resulting from guaiacol 
oxidation (Coll et al. 1993, Okino et al. 2000). The diameters of coloured zone and growth rate were measured in $\mathrm{mm}$. The white rot fungus Pleurotus ostreatus, a well known lignin-degrading fungus, was used as a positive control. Stock culture of Pleurotus ostreatus on millet grains was obtained from Mushroom Unit, Faculty of Agriculture, Mansoura University, Egypt and the spawn was kept at $4^{\circ} \mathrm{C}$ until used for inoculation.

Optimization of growth and laccase production medium - Chaetomium globosum isolated from Adiantum capillus-veneris, as a high producer of extracellular laccase was maintained on $\mathrm{OA}$ slants at $30^{\circ} \mathrm{C}$ for 7 days. Fungal spore suspension was prepared by adding $5 \mathrm{ml}$ of sterile distilled water to freshly (7 days) grown cultures. The suspension was used to inoculate different media $(100 \mathrm{ml})$ in Erlenmeyer flasks $(250 \mathrm{ml})$.

In this study laccase production at different $\mathrm{pH}$ values $(3,4,5,6,7,8,9)$ were analyzed and $\mathrm{pH}$ values were adjusted to the desired value by using $0.1 \mathrm{M} \mathrm{HCl}$. The flasks were then incubated at different temperatures $\left(25,30,35,40\right.$ and $\left.45^{\circ} \mathrm{C}\right)$. For a time course study, the flasks were incubated on a gyratory shaker with shaking at $200 \mathrm{rpm}$ at $30^{\circ} \mathrm{C}$ for 10 days.

Various carbon sources at $1 \%$ final concentration were tested for laccase production instead of glucose using a synthetic medium (Viswanath et al. 2008) consisting of $0.3 \%$ peptone, $0.06 \% \quad \mathrm{KH}_{2} \mathrm{PO}_{4}, \quad 0.0001 \%$

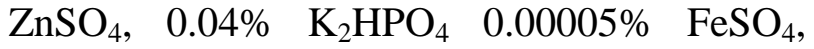

$0.005 \% \mathrm{MnSO}_{4}$ and $0.05 \% \mathrm{MgSO}_{4}$ prepared in distilled water without inclusion of an inducer (0.02\% guaiacol). The carbon sources included monosaccharide hexoses (fructose, galactose and rhamnose); monosaccharide pentose (xylose); disaccharides (sucrose, maltose, and lactose); sugar-alcohols (glycerol) and the polysaccharide (starch). Various nitrogen sources included inorganic nitrogen (potassium nitrate, sodium nitrate, ammonium nitrate); amino acid (glycine) and complex organic source (peptone and beef extract) at $0.3 \%$ final concentration were examined for laccase production.

At one day interval, flasks with growing culture of Chaetomium globosum were withdrawn and each sample was monitored for fungal growth, $\mathrm{pH}$, and laccase activities. The culture in each flask was aseptically filtered through pre-weighed filter paper (Whatman No 1), mycelium dried at $70^{\circ} \mathrm{C}$ in an oven and the filtrate was centrifuged at $10000 \mathrm{rpm}$ at $4^{\circ} \mathrm{C}$ for 15 minutes. The supernatant obtained was treated as the enzyme extract.

Enzyme activity was assayed at $30^{\circ} \mathrm{C}$ by using $10 \mathrm{mM}$ guaiacol in $100 \mathrm{mM}$ acetate buffer containing $10 \% \quad(\mathrm{v} / \mathrm{v})$ acetone. Absorbance of blank was measured at $470 \mathrm{~nm}$, while the test samples with guaiacol were measured at $530 \mathrm{~nm}$ after 10 minutes of incubation. Enzyme activity is measured in $\mathrm{u} / \mathrm{ml}$ which is defined as the amount of enzyme catalyzing the production of one micromole of coloured product per minute per $\mathrm{ml}$.

\section{Calculation}

Volume activity $(u / \mathrm{ml})=\quad \underline{\Delta \mathrm{A}_{470 \mathrm{~nm}}} \frac{/ \mathrm{min} \times 4 \times \mathrm{Vt} \times \mathrm{x} \text { dilution factor }}{€ \times \mathrm{Vs}}$

Where,

$\mathrm{Vt}=$ final volume of reaction mixture $(\mathrm{ml})=5.00$

$\mathrm{Vs}=$ sample volume $(\mathrm{ml})=1$

$€=$ extinction co-efficient of guaiacol $=6,740 / \mathrm{M} / \mathrm{cm}$

$4=$ derived from unit definition $\&$ principle

Data analyses - The frequency of isolated taxa is expressed as number of cases of isolation of each species out of the total number of studied sites, while species diversity is calculated as Simpson's diversity index (Lande 1996). 


\section{Results}

General features of isolated fungi - As shown in Table 2 it was possible to encounter as many as 59 species (108775 CFU) belonging to 33 genera from the various sources under investigation namely: soil, wood, seaweeds, sponge, ascidia, drifted wood, plants and miscellaneous materials.

Zygomycota was represented by six species $(10.16 \%$ of the total species number), teleomorphic Ascomycota (9 species, 15.25\%), anamorphic Ascomycota (44 species, 74.57\%) and Basidiomycota (1 species, 1.69\%). The prevailing genera were Aspergillus (15 species including anamorph stages of one Emericella and two Eurotium species; $25.42 \%$ of the total isolates), Penicillium (7 species including anamorph stage of Talaromyces, $11.86 \%$ ), Mucor (3 species; 5.08 \%), Fusarium, Trichoderma and Ulocladium (2 species each, $3.38 \%$ ). The remaining taxa were represented by only one species each. The most abundant species were: Aspergillus niger (31.45\% of the total isolates), A. flavus (16.24\%), Penicillium aurantiogriseum (8.78\%), and Macrophomina phaseolina $(5.08 \%)$.

Taxonomically, isolated species were assigned to 3 phyla with 4 classes, 11 orders, and 15 families. Taxa with uncertain position were distributed among classes, orders and families. Order Eurotiales accommodated the most species (23), while the orders Capnodiales, Cantharellales, Onygenales and Microascales accommodated only one species each. Family Trichocomaceae had the highest contribution to the isolated fungi (23 species out of 60) followed by Pleosporaceae (6 species), Mucoraceae (4 species) and the remaining families were represented each by only one or two species.

The species genus ratio $(\mathrm{S} / \mathrm{G})$ per family however shows that family Trichocomaceae was the most diverse taxonomical rank by recording a ratio of 3.8 followed by Mucoraceae and Pleosporaceae. In view of species richness, soil showed the highest richness index of fungi species (species richness $=42$ ) among all studied habitats and followed by sponge (12 species). The remaining habitats showed moderate to poor species richness ranging from 1 to 9 .
The distribution pattern of mycobiota based on the presence/absence in habitats under investigation is shown in Figure 1. It is clear from the figure that recorded taxa could be tentatively classified into three groups. Group 1 , comprises taxa of occurrence restricted to a single habitat (38 species) e.g. Sordaria fimicola, Aspergillus ustus, Aureobasidium pullulans and Stemphylium botryosum. Group 2 , consists of species occurring in two or more habitats but showing some sort of preference for higher occurrence in one of them (18 species) e.g. Fusarium solani, Gymnascella dankaliensis, Aspergillus japonicus and A. fumigatus. Group 3, contains species of common occurrence to almost all habitats (4 species) e.g. Aspergillus niger, A. flavus, Penicillium aurantiogriseum and Trichoderma pseudokoningii.

The diversity of fungi was measured for each habitat by calculating Simpson's diversity index (Lande 1996). Based on the results, soil showed the highest diversity index (Table 4) of 0.83 while contaminated wax samples and Adiantum capillus-veneris showed the lowest value (0).

\section{Screening and qualitative assessment of laccase producing taxa}

Out of 60 species screened in this study, only fifteen taxa had laccase activity compared with Pleurotus ostreatus as a positive control to differentiate between growth and oxidation characteristics. Thirteen species of Ascomycota, one Basidiomycota (Thanatephorus cucumeris) and one Zygomycota (Mucor circinelloids) showed laccase production activity (Table 5).

Results showed that, the endophytic fungal isolates came first by showing high laccase production activity in comparison with other taxa isolated from different ecological habitats. Chaetomium globosum measured about $40 \mathrm{~mm}$ colour zone diameter and $55 \mathrm{~mm}$ growth colony diameter on the 7th day of cultivation, followed by Phoma exigua $(32 \mathrm{~mm}$ and $50 \mathrm{~mm}$, respectively), Thanatephorus cucumeris (23 and $30 \mathrm{~mm}$ ) and Sordaria fimicola (23 and $59 \mathrm{~mm}$ ).

Fungal taxa isolated from marine sources showed degrees of oxidation scale ranging between weak to high. Mucor 
Table 2 Total count (TC, colonies/ g), number of isolations (NCI, out of 520 samples) and percentage frequency of fungal taxa recovered on isolation media at $28^{\circ} \mathrm{C}$

\begin{tabular}{|c|c|c|c|}
\hline Species & $\mathbf{T C}$ & NC1 & $\% \mathbf{F}$ \\
\hline \multicolumn{4}{|c|}{ Zygomycota } \\
\hline Lichtheimia corymbifera (Cohn) Vuill. & 97 & 2 & 0.38 \\
\hline Mucor circinelloid Tiegh. & 258 & 13 & 2.50 \\
\hline M. hiemalis Wehmer & 598 & 8 & 1.54 \\
\hline M. racemosus Fresen. & 35 & 2 & 0.38 \\
\hline Rhizopus stolonifer (Ehrenb.) Vuill. & 365 & 9 & 1.73 \\
\hline Syncephalastrum racemosum Cohn ex J. Schröt. & 168 & 4 & 0.77 \\
\hline \multicolumn{4}{|l|}{ Ascomycota (teleomorphic) } \\
\hline Achaetomium macrosporum Rai, Wadhwani \& J.P. Tewari & 457 & 6 & 1.15 \\
\hline Chaetomium globosum Kunze & 5049 & 67 & 12.88 \\
\hline Emericella nidulans (Eidam) Vuill. & 921 & 17 & 3.27 \\
\hline Eurotium amstelodami L. Mangin & 190 & 4 & 0.77 \\
\hline E. chevalieri L. Mangin & 163 & 5 & 0.96 \\
\hline Gymnascella dankaliensis (Castell.) Currah & 496 & 20 & 3.85 \\
\hline Microascus cinereus Curzi & 188 & 6 & 1.15 \\
\hline Sordaria fimicola (Roberge ex Desm.) Ces. \& De Not. & 17 & 4 & 0.77 \\
\hline Talaromyces flavus (Klöcker) Stolk \& Samson & 33 & 5 & 0.96 \\
\hline \multicolumn{4}{|l|}{ Ascomycota (anamorphic)* } \\
\hline Acremonium restrictum (J.F.H. Beyma) W. Gams & 989 & 3 & 0.58 \\
\hline A. rutilum W. Gams & 1230 & 7 & 1.35 \\
\hline Acrophialophora fusispora (S.B. Saksena) Samson & 50 & 7 & 1.35 \\
\hline Agonomycete & 277 & 14 & 2.69 \\
\hline Alternaria alternata (Fr.) Keissl. & 279 & 23 & 4.42 \\
\hline Aspergillus candidus Link & 27 & 6 & 1.15 \\
\hline A. flavus Link & 17664 & 151 & 29.04 \\
\hline A.fumigatus Fresen & 869 & 5 & 0.96 \\
\hline A.japonicus Saito & 144 & 18 & 3.46 \\
\hline A.niger Tiegh. & 34312 & 209 & 40.19 \\
\hline A. ochraceous $\mathrm{G}$. Wilh. & 734 & 7 & 1.35 \\
\hline A.sydowii (Bainier \& Sartory) Thom \& Church & 197 & 2 & 0.38 \\
\hline A. tamarii Kita & 1357 & 26 & 5.00 \\
\hline A. terreus Thom & 1349 & 5 & 0.96 \\
\hline A. ustus (Bainier) Thom \& Church & 470 & 5 & 0.96 \\
\hline A. versicolor (Vuill.) Tirab. & 897 & 6 & 1.15 \\
\hline A. wentii Wehmer & 100 & 1 & 0.19 \\
\hline Aureobasidium pullulans (de Bary) G. Arnaud & 3754 & 2 & 0.38 \\
\hline Botryotrichum piluliferum Sacc. \& Marchal & 29 & 9 & 1.73 \\
\hline Cladosporium cladosporioides (Fresen.) de Vries & 504 & 64 & 12.31 \\
\hline Curvularia lunata (Wakker) Boedijn & 7 & 3 & 0.58 \\
\hline Drechslera spicifera (Bainier) Arx & 208 & 14 & 2.69 \\
\hline Fusarium oxysporum Schltdl. & 175 & 16 & 3.08 \\
\hline F. solani (Mart.) Sacc. & 5493 & 11 & 2.12 \\
\hline Humicola fuscoatra Traaen & 433 & 6 & 1.15 \\
\hline Lasiodiplodia theobromae (Pat.) Griffon \& Maubl. & 61 & 9 & 1.73 \\
\hline Macrophomina phaseolina (Tassi) Goid. & 5535 & 7 & 1.35 \\
\hline Myrothecium roridum Tode & 47 & 5 & 0.96 \\
\hline Paecilomyces varioti Bainier & 367 & 6 & 1.15 \\
\hline Penicillium aurantiogriseum Dierckx & 9553 & 63 & 12.12 \\
\hline$P$. brevi-compactum Dierckx & 927 & 34 & 6.54 \\
\hline P. canescens Sopp & 848 & 8 & 1.54 \\
\hline P. chrysogenum Thom & 5075 & 42 & 8.08 \\
\hline P. purpurogenum Stoll & 2420 & 2 & 0.38 \\
\hline P. variabile Sopp & 89 & 2 & 0.38 \\
\hline Phoma exigua var. exigua Desm. & 32 & 11 & 2.12 \\
\hline Sarocladium strictum (W. Gams) Summerb. & 332 & 36 & 6.92 \\
\hline Stachybotrys chartarum (Ehrenb.) S. Hughes & 23 & 3 & 0.58 \\
\hline Stemphylium botryosum Sacc. & 73 & 9 & 1.73 \\
\hline
\end{tabular}


Mycosphere Doi 10.5943/mycosphere/3/6/4

\begin{tabular}{|c|c|c|c|c|}
\hline Species & & $\mathbf{T C}$ & NC1 & $\% \mathrm{~F}$ \\
\hline \multicolumn{2}{|l|}{ Trichoderma pseudokoningii Rifai } & 988 & 44 & 8.46 \\
\hline \multicolumn{2}{|l|}{ T. viride Pers. } & 283 & 31 & 5.96 \\
\hline \multicolumn{2}{|l|}{ Ulocladium atrum Preuss } & 38 & 6 & 1.15 \\
\hline \multicolumn{2}{|l|}{ U. botrytis Preuss } & 86 & 5 & 0.96 \\
\hline \multirow[t]{2}{*}{ Yeast } & & 1327 & 17 & 3.27 \\
\hline & Basidiomycota & & & \\
\hline \multirow{2}{*}{\multicolumn{2}{|c|}{$\begin{array}{l}\text { Thanatephorus cucumeris (A.B. Frank) Donk } \\
\text { Total }\end{array}$}} & 88 & 7 & 1.35 \\
\hline & & 108775 & & \\
\hline
\end{tabular}

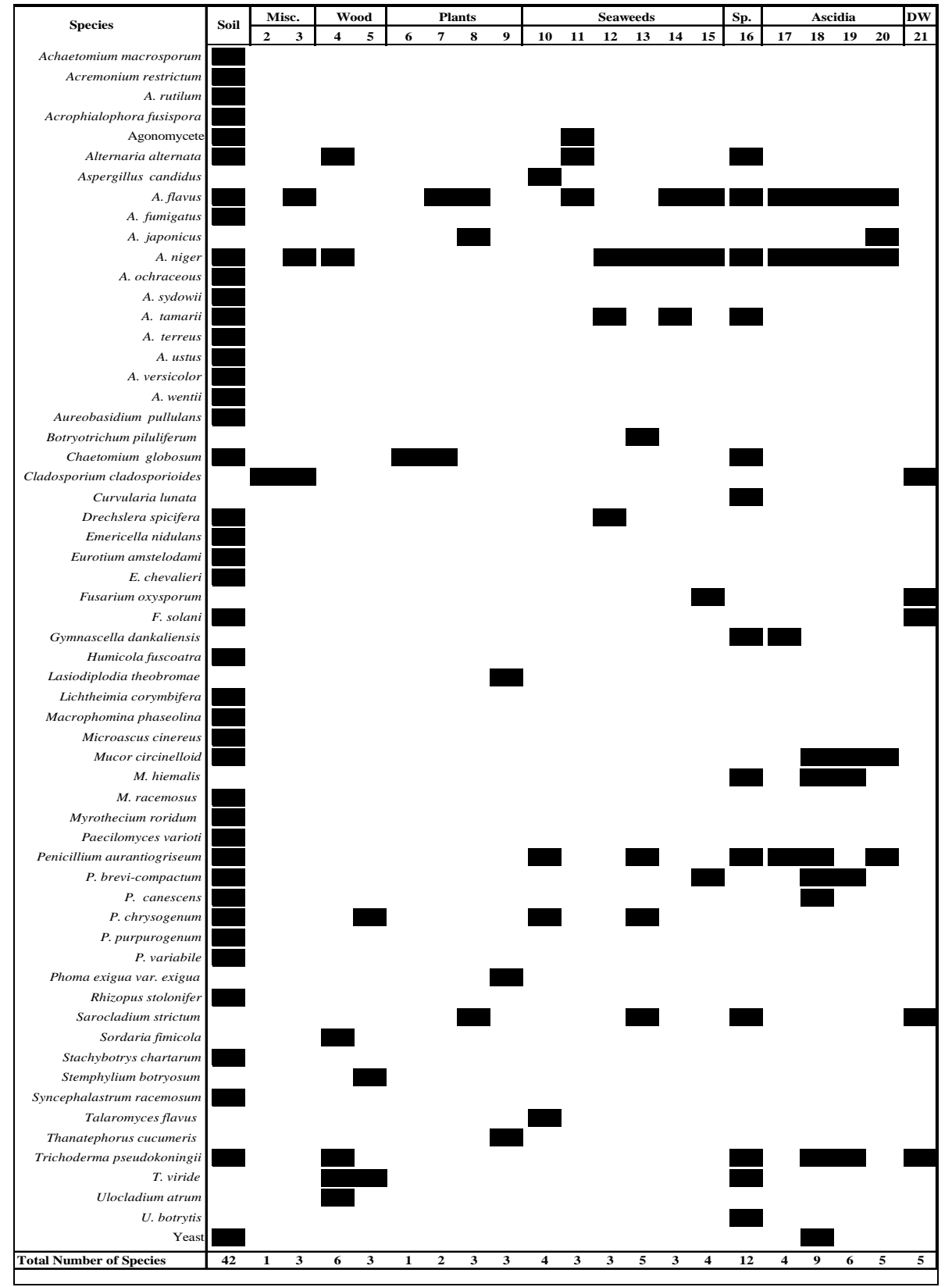

Fig. 1 - Distribution of isolated taxa in different environmental habitats and sites where: 2= contaminated wax samples, $3=$ contaminated water colours, $4=$ Acacia tortilis subsp. raddiana wood, 5= Ceratonia siliqua wood, $6=$ Adiantum capillus-veneris, $7=$ Phlomis aurea, $8=$ Alkanna orientalis, 9= roots of Phlomis aurea and Alkanna orientalis, 10=Ulva lactuca, 11= Caulerpa serrulata, $12=C$. prolifera, 13= Hypnea cornuta, 14= Sarconema filiforme, 15= Cystoseira myrica, 16= Hippospongia communis, 17= Phallusia nigra, 18= Micsocosmus pupa, 19= Styela plicata, 20= Polyclinum constellatum and $21=$ drifted decaying wood. 
Table 4 Simpson diversity index of all studied habitats.

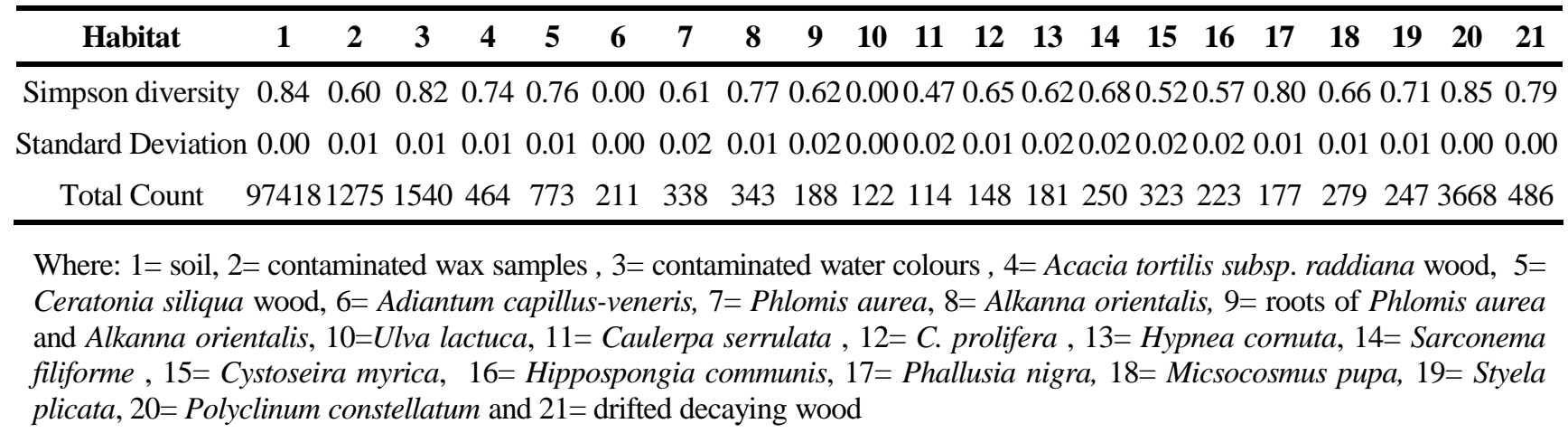

circinelloid (isolated from ascidia) and Aspergillus tamarii (from seaweeds) showed weak activity (Table 5), while Agonomycete, isolated from green seaweed, measured about 5 $\mathrm{mm}$ colour zone diameter and $12 \mathrm{~mm}$ growth colony diameter (moderate laccase activity). Both marine isolates of Talaromyces flavus and Aspergillus candidus were similar in their oxidation scale and growth, having 28, 25 and $28,38 \mathrm{~mm}$, respectively.

The fungal endophyte isolates Ulocladium atrum and Alternaria alternata showed moderate to high oxidation $(14,19 \mathrm{~mm}$ and 19, $21 \mathrm{~mm}$, respectively). Other terricolous taxa e.g. Aureobasidium pullulans, Penicillium purpurogenum and Stachybotrys chartarum have the lowest oxidation activity in comparison with the previous taxa.

Optimization of laccase production Production and activity of laccase was measured by culturing of Chaetomium globosum in medium containing different carbon and nitrogen sources at different incubation degrees and $\mathrm{pH}$. Maximum production of laccase $(13.3 \mu / \mathrm{ml})$ was reached on the $6^{\text {th }}$ day of incubation in culture broths with maximum biomass between 5-7 days (145-172 mg dry weight).

The optimum $\mathrm{pH}$ and incubation temperature were at 7 and $30{ }^{\circ} \mathrm{C}$, respectively. High level of laccase production was recorded using maltose $(3.12 \mu / \mathrm{ml})$ out of the 9 different carbon sources followed by glycerol in comparison with glucose. Other carbon sources had poor growth of the fungus and production of laccase. Laccase production is induced by using peptone in comparison with the five examined nitrogen sources, which showed reduced rate of laccase production. Results of potassium nitrate and sodium nitrate as nitrogen source came second after peptone (2.8 $\mu / \mathrm{ml}$ ), while beef extract was a very poor nitrogen source for production of laccase. Finally, we observed that there is a high increase in laccase production $(13.3 \mu / \mathrm{ml})$ when the culture is grown in optimum medium composed of $1 \%$ maltose, $0.3 \%$ peptone, $0.06 \% \quad \mathrm{KH}_{2} \mathrm{PO}_{4}, \quad 0.0001 \% \quad \mathrm{ZnSO}_{4}, \quad 0.0 \% 4$ $\mathrm{K}_{2} \mathrm{HPO}_{4} 0.00005 \% \mathrm{FeSO}_{4}, 0.005 \% \mathrm{MnSO}_{4}$ and $0.05 \% \mathrm{MgSO}_{4}$ at $\mathrm{pH} 7$ and $30^{\circ} \mathrm{C}$ (Figs. 3-8).

Table 5 Qualitative assay for laccase enzyme production

\begin{tabular}{|c|c|c|c|c|}
\hline \multirow[b]{2}{*}{ Fungal Isolate } & \multirow[b]{2}{*}{ Source of Isolation ${ }^{a}$} & \multicolumn{3}{|c|}{ Mycelial growth and oxidation characteristics } \\
\hline & & $\begin{array}{l}\text { Color zone diameter } \\
(\mathrm{mm})^{\mathbf{b}}\end{array}$ & $\begin{array}{l}\text { Oxidation } \\
\text { Scale }^{\mathbf{c}}\end{array}$ & $\begin{array}{r}\text { Fungal colony } \\
\text { diameter }(\mathrm{mm})^{\mathbf{d}}\end{array}$ \\
\hline \multicolumn{5}{|c|}{ Zygomycota } \\
\hline Lichtheimia corymbifera & $\mathrm{S}$ & - & - & $60 \mathrm{~mm}$ \\
\hline Mucor circinelloid & As, $\mathrm{S}$ & $4 \mathrm{~mm}$ & + & $54 \mathrm{~mm}$ \\
\hline M. hiemalis & As, $\mathrm{Sp}$ & - & - & $60 \mathrm{~mm}$ \\
\hline M. racemosus & $\mathrm{S}$ & - & - & $39 \mathrm{~mm}$ \\
\hline Rhizopus stolonifer & $\mathrm{S}$ & - & - & $70 \mathrm{~mm}$ \\
\hline Syncephalastrum racemosum & $\mathrm{S}$ & - & - & $35 \mathrm{~mm}$ \\
\hline \multicolumn{5}{|c|}{ Ascomycota (teleomorphic) } \\
\hline Achaetomium macrosporum & $\mathrm{S}$ & - & - & $67 \mathrm{~mm}$ \\
\hline Chaetomium globosum & $\mathrm{P}, \mathrm{S}, \mathrm{Sp}$ & $40 \mathrm{~mm}$ & +++++ & $58 \mathrm{~mm}$ \\
\hline Emericella nidulans & $\mathrm{S}$ & - & - & $25 \mathrm{~mm}$ \\
\hline Eurotium amstelodami & $\mathrm{S}$ & - & - & $28 \mathrm{~mm}$ \\
\hline
\end{tabular}


Mycosphere Doi 10.5943/mycosphere/3/6/4

\begin{tabular}{|c|c|c|c|c|}
\hline \multirow[b]{2}{*}{ Fungal Isolate } & \multirow[b]{2}{*}{ Source of Isolation ${ }^{\text {a }}$} & \multicolumn{3}{|c|}{ Mycelial growth and oxidation characteristics } \\
\hline & & $\begin{array}{l}\text { Color zone diameter } \\
(\mathrm{mm})^{\mathbf{b}}\end{array}$ & $\begin{array}{c}\text { Oxidation } \\
\text { Scale }^{\mathbf{c}}\end{array}$ & $\begin{array}{r}\text { Fungal colony } \\
\text { diameter }(\mathrm{mm})^{\mathbf{d}}\end{array}$ \\
\hline E. chevalieri & $\mathrm{S}$ & - & - & $26 \mathrm{~mm}$ \\
\hline Gymnascella dankaliensis & As, $\mathrm{Sp}$ & - & - & $34 \mathrm{~mm}$ \\
\hline Microascus cinereus & $\mathrm{S}$ & - & - & $15 \mathrm{~mm}$ \\
\hline Sordaria fimicola & $\mathrm{W}$ & $23 \mathrm{~mm}$ & ++++ & $59 \mathrm{~mm}$ \\
\hline $\begin{array}{l}\text { Talaromyces flavus } \\
\text { Ascomycota (anamorphic)* }\end{array}$ & GS & $28 \mathrm{~mm}$ & ++++ & $28 \mathrm{~mm}$ \\
\hline Acremonium restrictum & $\mathrm{S}$ & - & - & $30 \mathrm{~mm}$ \\
\hline A. rutilum & S & - & - & $32 \mathrm{~mm}$ \\
\hline Acrophialophora fusispora & $\mathrm{S}$ & - & - & $27 \mathrm{~mm}$ \\
\hline Agonomycete & GS, S & $12 \mathrm{~mm}$ & ++ & $5 \mathrm{~mm}$ \\
\hline Alternaria alternata & GS, S, Sp, W & $19 \mathrm{~mm}$ & +++ & $21 \mathrm{~mm}$ \\
\hline Aspergillus candidus & GS & $25 \mathrm{~mm}$ & ++++ & $38 \mathrm{~mm}$ \\
\hline \multirow[t]{2}{*}{ A. flavus } & As, BS, GS, P, RS, & & & \\
\hline & $\mathrm{S}, \mathrm{Sp}, \mathrm{Wc}$ & - & - & $53 \mathrm{~mm}$ \\
\hline A.fumigatus & $\mathrm{S}$ & - & - & $23 \mathrm{~mm}$ \\
\hline A.japonicus & As, $\mathrm{P}$ & - & - & $45 \mathrm{~mm}$ \\
\hline A.niger & $\begin{array}{l}\text { As, BS, GS, RS, S, } \\
\text { Sp, Wc, W }\end{array}$ & - & - & $55 \mathrm{~mm}$ \\
\hline A. ochraceous & $\mathrm{S}$ & - & - & $22 \mathrm{~mm}$ \\
\hline A.sydowii & S & - & - & $17 \mathrm{~mm}$ \\
\hline A. tamarii & Gs, Rs, S, Sp & $7 \mathrm{~mm}$ & + & $18 \mathrm{~mm}$ \\
\hline A. terreus & $\mathrm{S}$ & - & - & $15 \mathrm{~mm}$ \\
\hline A. ustus & S & - & - & $9 \mathrm{~mm}$ \\
\hline A. versicolor & S & - & - & $12 \mathrm{~mm}$ \\
\hline A. wentii & $\mathrm{S}$ & - & - & $9 \mathrm{~mm}$ \\
\hline Aureobasidium pullulans & $S$ & $4 \mathrm{~mm}$ & + & $6 \mathrm{~mm}$ \\
\hline Botryotrichum piluliferum & RS & - & - & $8 \mathrm{~mm}$ \\
\hline Cladosporium cladosporioides & Dw, Wc, Wx & & - & $34 \mathrm{~mm}$ \\
\hline Curvularia lunata & $\mathrm{Sp}$ & $9 \mathrm{~mm}$ & + & $19 \mathrm{~mm}$ \\
\hline Drechslera spicifera & GS, S & - & - & $11 \mathrm{~mm}$ \\
\hline Fusarium oxysporum & BS, Dw & - & - & $10 \mathrm{~mm}$ \\
\hline F. solani & Dw, $S$ & - & - & $13 \mathrm{~mm}$ \\
\hline Humicola fuscoatra & $S$ & - & - & $8 \mathrm{~mm}$ \\
\hline Lasiodiplodia theobromae & $\mathrm{P}$ & - & - & $11 \mathrm{~mm}$ \\
\hline Macrophomina phaseolina & $\mathrm{S}$ & - & - & $17 \mathrm{~mm}$ \\
\hline Myrothecium roridum & $\mathrm{S}$ & - & - & $15 \mathrm{~mm}$ \\
\hline Paecilomyces variotii & $\mathrm{S}$ & - & - & $22 \mathrm{~mm}$ \\
\hline Penicillium aurantiogriseum & As, GS, RS, S & - & - & $19 \mathrm{~mm}$ \\
\hline P. brevi-compactum & As, BS, S & - & - & $50 \mathrm{~mm}$ \\
\hline$P$. canescens & $\mathrm{S}$ & - & - & $60 \mathrm{~mm}$ \\
\hline P. chrysogenum & As, GS, RS, S, W & - & - & $25 \mathrm{~mm}$ \\
\hline P. purpurogenum & $\mathrm{S}$ & $8 \mathrm{~mm}$ & + & $11 \mathrm{~mm}$ \\
\hline P. variabile & $\mathrm{S}$ & - & - & $22 \mathrm{~mm}$ \\
\hline Phoma exigua var. exigua & $\mathrm{R}$ & $32 \mathrm{~mm}$ & ++++ & $50 \mathrm{~mm}$ \\
\hline Sarocladium strictum & Dw, P, Sp, RS & - & - & $8 \mathrm{~mm}$ \\
\hline Stachybotrys chartarum & $\mathrm{S}$ & $17 \mathrm{~mm}$ & +++ & $19 \mathrm{~mm}$ \\
\hline Stemphylium botryosum & $\mathrm{W}$ & - & - & $58 \mathrm{~mm}$ \\
\hline Trichoderma pseudokoningii & As, Dw, S, Sp, W & - & - & $70 \mathrm{~mm}$ \\
\hline Trichoderma viride & $\mathrm{Sp}, \mathrm{W}$ & - & - & $64 \mathrm{~mm}$ \\
\hline Ulocladium atrum & $\mathrm{W}$ & 13 & ++ & $19 \mathrm{~mm}$ \\
\hline$U$. botrytis & $\mathrm{Sp}$ & - & $\begin{array}{c}- \\
\text { Basidiomycota }\end{array}$ & $22 \mathrm{~mm}$ \\
\hline Thanatephorus cucumeris & $\mathrm{R}$ & $23 \mathrm{~mm}$ & ++++ & $30 \mathrm{~mm}$ \\
\hline * Pleurotus ostreatus & & 38 & +++++ & 24 \\
\hline
\end{tabular}

${ }^{\mathrm{a}}$ Where: As= Ascidia, BS= Brown Seaweeds, Dw= Drifted Wood, GS= Green Seaweeds, $\mathrm{P}=$ Plants, R= Root, RS= Red Seaweeds, $\mathrm{S}=\mathrm{Soil}, \mathrm{Sp}=$ Sponge, $\mathrm{W}=\mathrm{Wax}, \mathrm{W}=\mathrm{Wood}, \mathrm{Wc}=$ Water colors

* Pleurotus ostreatus a well known lignin-degrading white rot fungus used as a positive control.

${ }^{\mathrm{b}}$ Diameter of the oxidized zone in mm (measured on the $7^{\text {th }}$ day of cultivation).

${ }^{\mathrm{c}}$ Oxidation scale measured on the $7^{\text {th }}$ day of cultivation on modified Czapek's agar medium containing $0.02 \%$ guaiacol: + diameter of the oxidized zone $0-10 \mathrm{~mm}$, ++ zone diameter 11-15 mm, +++ zone diameter 16-20 mm, ++++ zone diameter 21-30 mm, +++++ zone diameter up to $31 \mathrm{~mm}$.

${ }^{\mathrm{d}}$ Diameter of the mycelial colony in mm measured on the $7^{\text {th }}$ day of cultivation (the initial disc $5 \mathrm{~mm}$ diameter). 


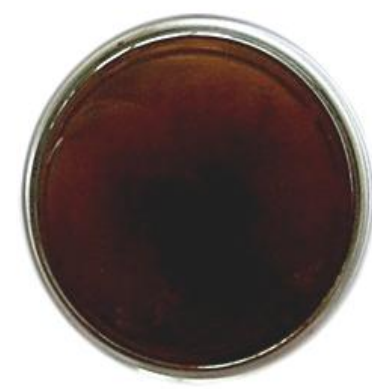

Chaetomium globosum

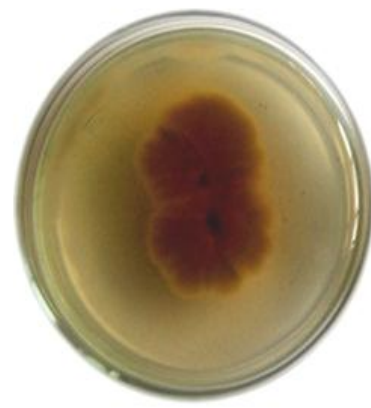

Aspergillus candidus

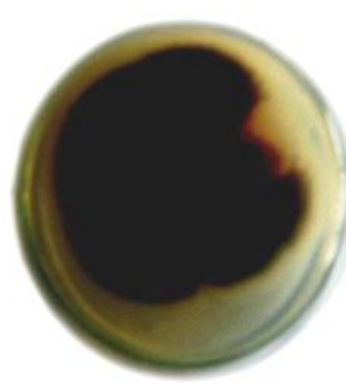

Phoma exigua

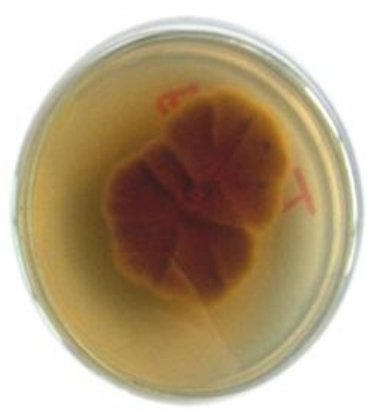

Talaromyces flavus

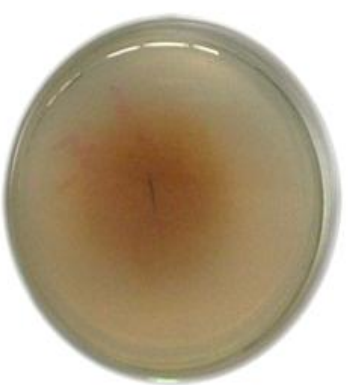

Thanatephorus cucumeris

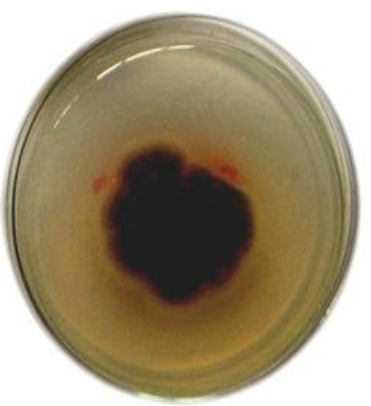

Agonomycete

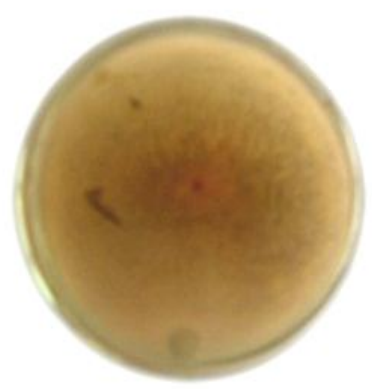

Mucor circinelloid

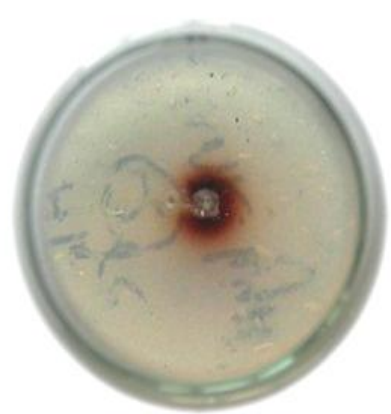

Curvularia lunta

Fig. 2 - Oxidative polymerization of guaiacol to form reddish brown zones in the medium.

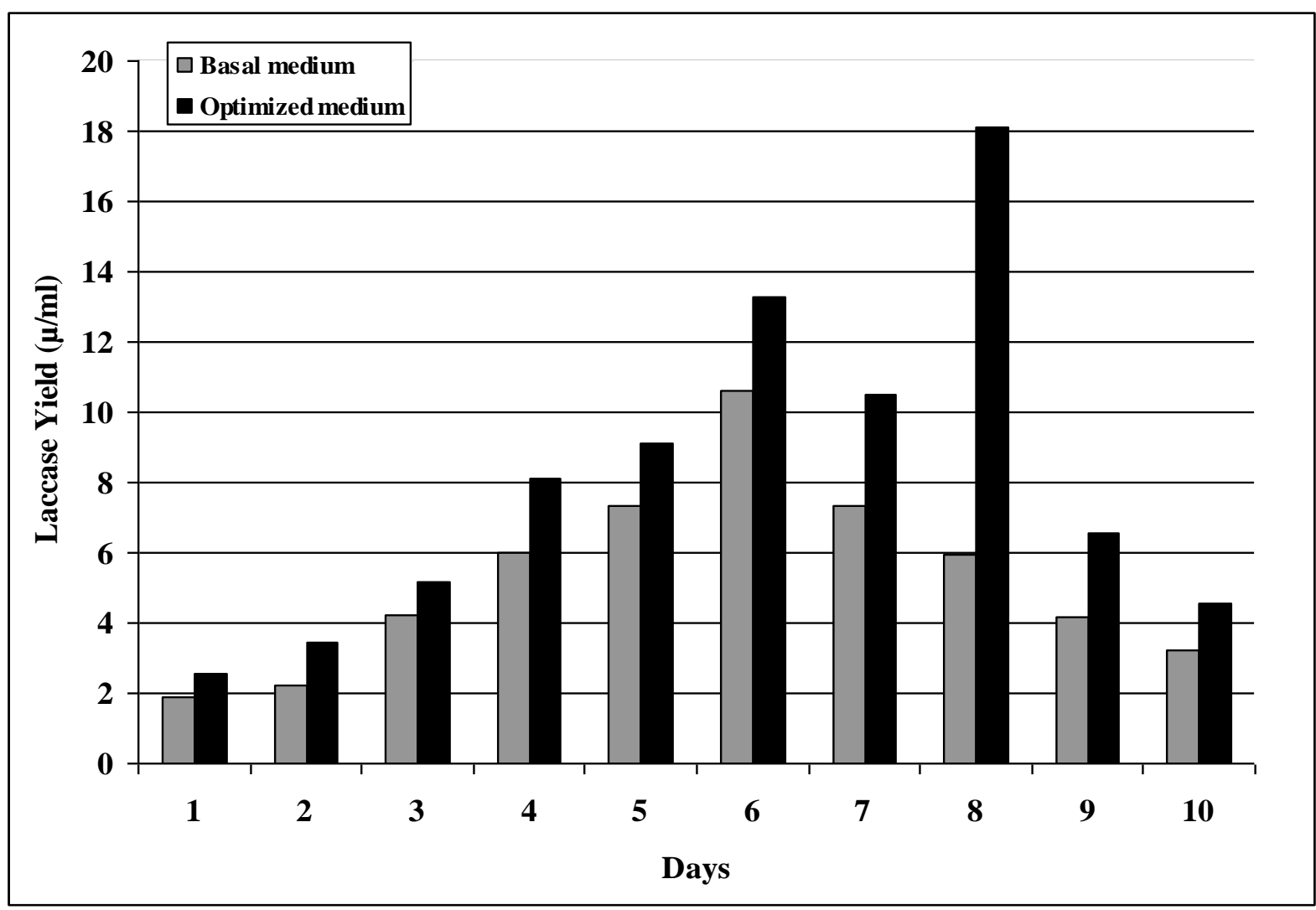

Fig. 3 - Laccase yield of Chaetomium globosum on basal and optimized media. 


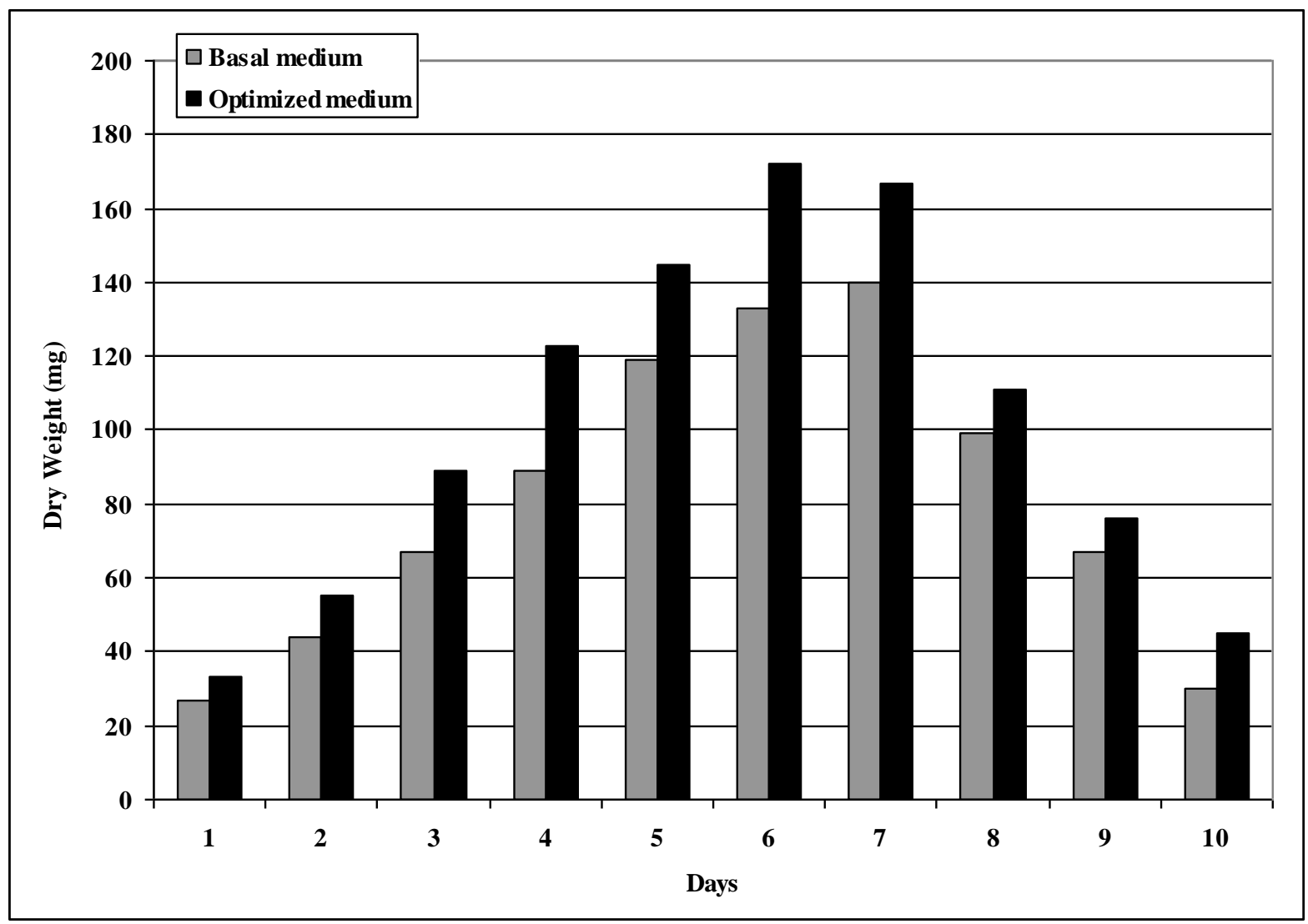

Fig. 4 - Dry weight (mg) of Chaetomium globosum on basal and optimized media.

\section{Discussion}

Saint Katherine wadis soils showed relatively low counts of fungal populations (97418 CFU in 20 sites) in comparison with the majority of Egyptian cultivated soil (AbdelAzeem 2009). In this study an average count of $4870.9 \mathrm{CFU} / \mathrm{g}$ was recorded. Most of the taxa have been isolated previously from Egyptian desert soils, but this is the first survey concerning laccase producing taxa in Saint Katherine World Heritage site. The structure of terricolous mycobiota in Saint Katherine area characterized by low counts associated with a narrow spectrum of species have been also reported by other investigators in different arid soils (Moubasher et al. 1985, Abdel-Hafez et al. 2000, Abdel-Sater 1999, Abdel-Azeem 1991, 2003, 2009, Abdel-Azeem \& Ibrahim 2004, Abdel-Moneim \& Abdel-Azeem 2009.

We found that the composition of marine-derived fungi isolated from seaweeds, drifted decaying wood, sponge and ascidia during this study in agreement with findings of Abdel-Moneim et al. 2010, Atalla et al. (2010).

It is noteworthy that the initial isolation and enumeration of the laccase producing taxa was not carried out by using a substrate specific selective medium, even though, about $25 \%$ of the isolates were found positive to laccase production. Fifteen species were recorded to produce laccase during this survey 13 of which were Ascomycota. This finding is in agreement with Hatakka (2001) who showed that Basidiomycota and saprobic fungi are the most widely known species that produce substantial amount of laccase in changeable quantity.

The optimal temperature range for fungal laccase activity ranges from $30^{\circ}$ to $60^{\circ} \mathrm{C}$ (Wood 1980, Youn et al. 1995, Nishizawa et al. 1995). Laccase from Chaetomium globosum examined in this study had an optimal temperature range of $30^{\circ} \mathrm{C}$, which is similar to that of values obtained for laccases from other taxa (Youn et al. 1995, D'Souza et al. 2006a, El-Zayat 2008, Viswanath et al. 2008). Phanerocheate chrysosporium, Pleurotus ostreatus and Ganoderma lucidum had an optimum temperature for growth and production of lignocellulose degrading enzymes of $25-35^{\circ} \mathrm{C}$ (Punnapayak et al. 2002). 


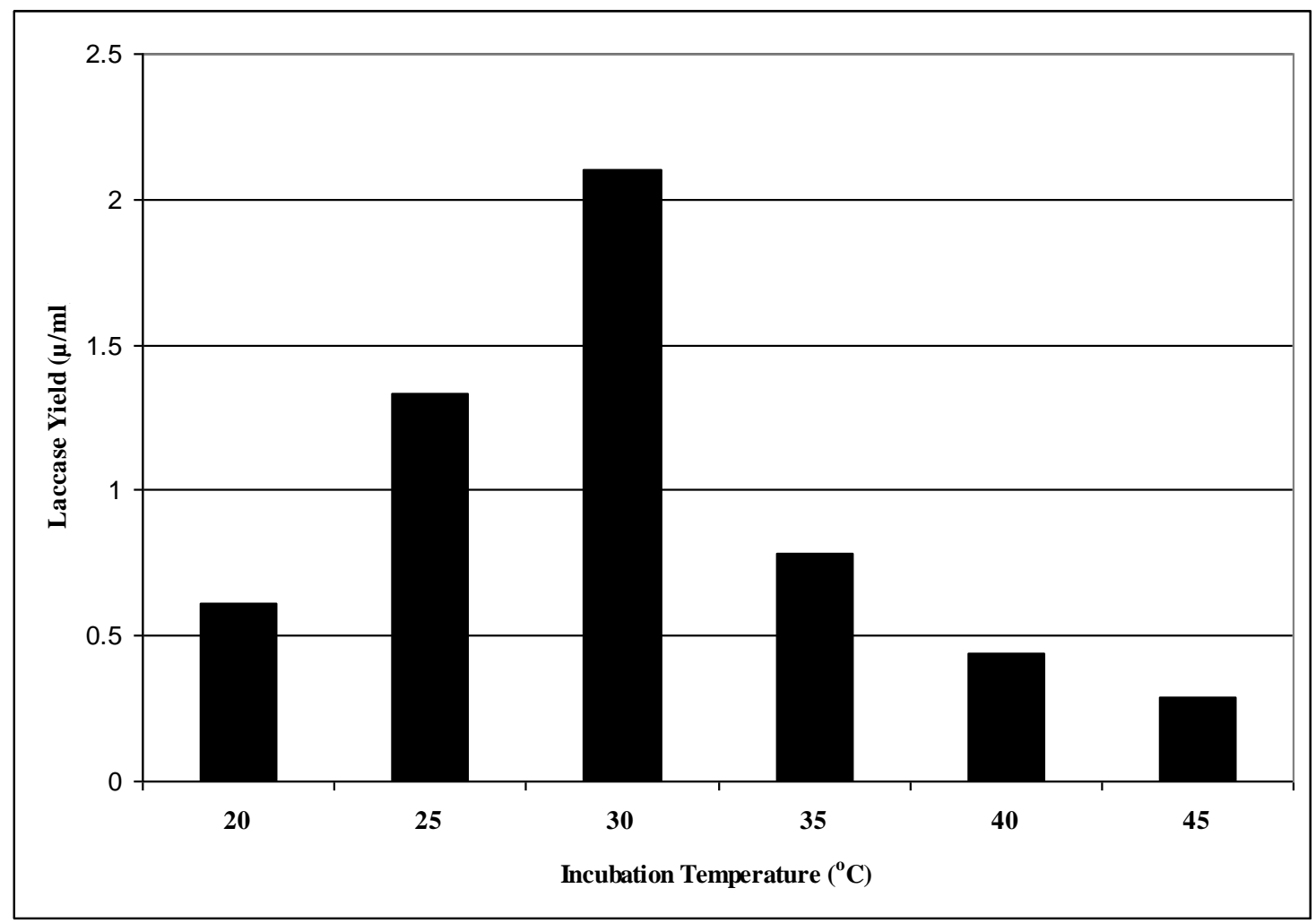

Fig. 5 - Effect of incubation temperature on laccase production by Chaetomium globosum.

The optimum $\mathrm{pH}$ for laccase activity reported in most fungi is between 3-5 (Galhaup et al. 2002, Jordaan \& Leukes 2003, Wesenberg et al. 2003, Niku-Paavola et al. 2004, D'Souza et al. 2006b). Laccase from Chaetomium globosum, has maximum activity at $\mathrm{pH}$ 7. This result is in agreement with studies by El-Zayat (2008), Nyanhongo et al. (2002) and Kunamneni et al. (2007). While others have mentioned that when fungi are grown at $\mathrm{pH}$ 5.0, laccase is produced in excess, most studies have shown that $\mathrm{pH}$ between 4.5 and 6.0 is suitable for enzyme production (Thurston 1994).

Most laccase synthesis was obtained when maltose was used as the carbon source and peptone as the nitrogen source; lower yields were obtained with an inorganic nitrogen source. These results are consistent with those of Mikiashvili et al. (2006), Wang et al. (2006) and El-Zayat (2008). The high activity of laccase obtained from the examined fungus, without inducer, is higher than that obtained from Lentinus spp. (Pukahutal et al. 2004) and than that from Chaetomium globosum (ElZayat 2008, Varnaite et al. 2011).

It can be concluded that the distribution pattern of mycobiota, based on the presence/absence in habitats under investigation, showed that recorded taxa (60 species ) can be classified into three groups. The first group comprises taxa of occurrence restricted to a single substrate (38 species); the second contains species occurring in two or more habitats but showing some sort of preference for higher occurrence in one of them (18 species); and the third of species common to almost all habitats (4 species). The endophyte isolate Chaetomium globosum was selected based on fast and high oxidation rate of guaiacol on agar plates. Culture conditions $(\mathrm{pH}$ of $7,30^{\circ} \mathrm{C}, 1 \%$ maltose as a carbon source and $0.3 \%$ peptone as a nitrogen source) increased laccase synthesis in submerged cultures of this species. In general the study underlines the need to explore not only more organisms but also lignocellulosic substrates with different composition to express and evaluate the real potential of fungi producing hydrolases and oxidases. In addition, the medium composition must be optimized for each enzyme producer taxon. The present study must be considered, therefore, as a preliminary one and additional investigations are warranted. 


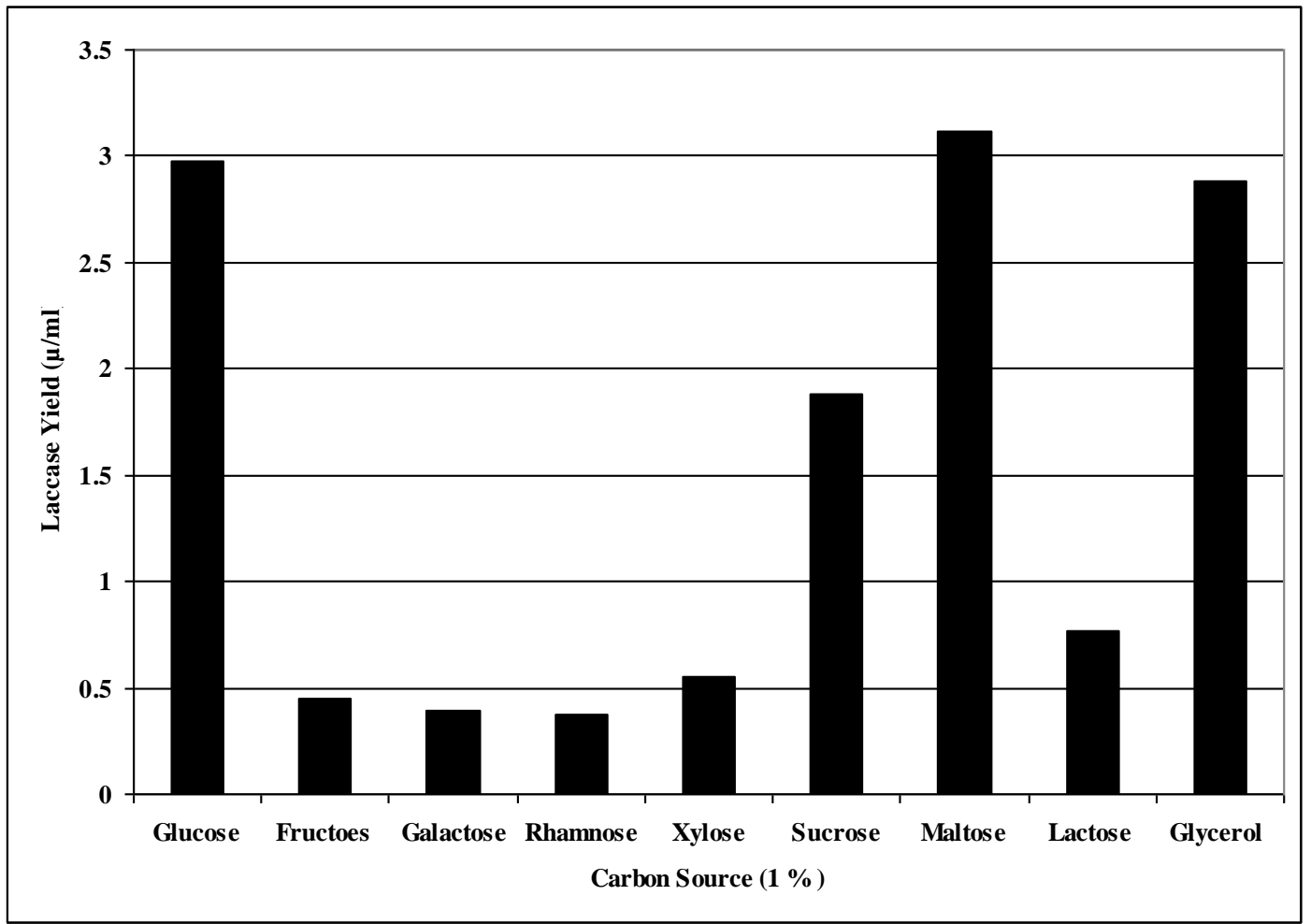

Fig. 6 - Various pH values in relation to laccase production by Chaetomium globosum.

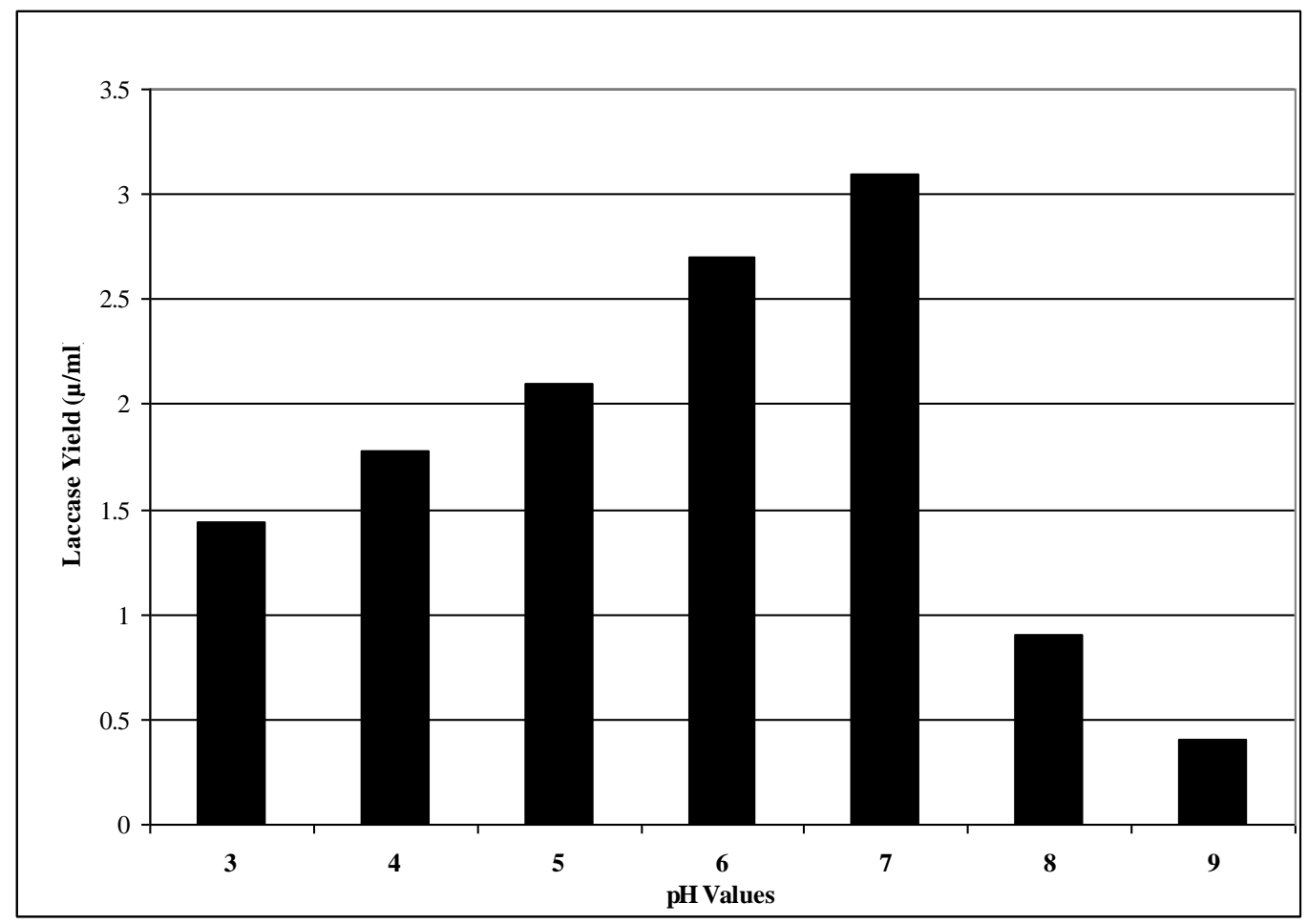

Fig. 7 - Effect of different carbon sources on laccase production by Chaetomium globosum at $30^{\circ} \mathrm{C}$. 


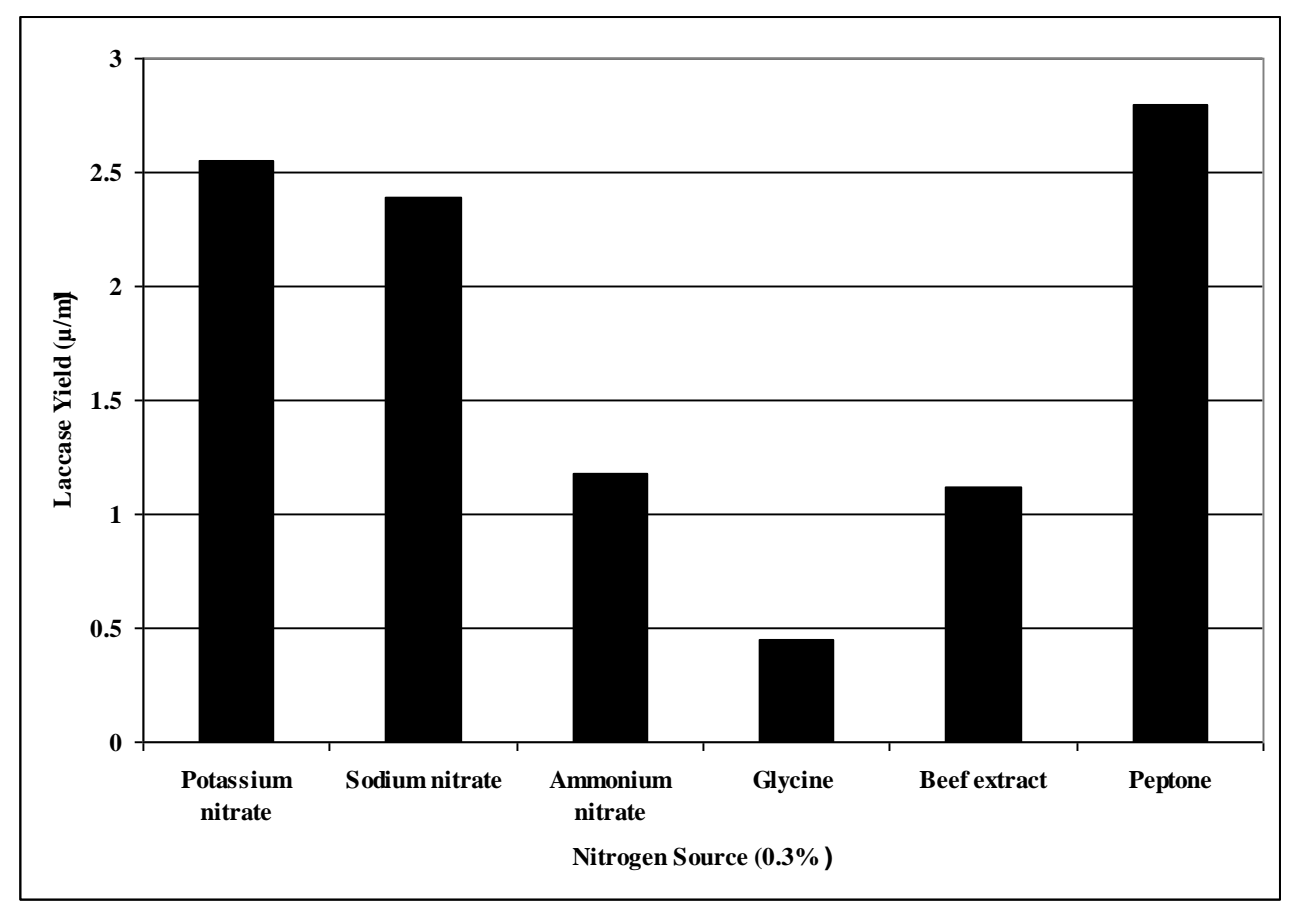

Fig. 8 - Effect of different nitrogen sources on laccase production by Chaetomium globosum at $30^{\circ} \mathrm{C}$.

\section{Acknowledgments}

We thank El-Sayda Mohamed Gamal El-Din (Botany Department, Faculty of Science, University of Suez Canal) for identification of plant species, Mohamed M. Hegazy (Marine Science Department, Faculty of Science, Suez Canal University) for providing seaweeds samples, Mohamed El-Shenawy (National Institute of Oceanography and Fisheries, Alexandria) for providing sponge samples and Gabriel Mahmoud Abo-Zied (Marine Science Department, Faculty of Science, University of Suez Canal) for collection and identification of ascidia. We are further indebted to Nehad M. Abdel-Moneim (Department of Biochemistry, Faculty of Science, Alexandria University) for her unfailing help during the part of optimization of enzyme in this work. We also owe thanks to Gihan S. Soliman for critical reading of the manuscript, Akram H. Mohamed for collection of some plant samples and to Kari T. Steffen (Department of Food and Environmental Sciences, Faculty of Agriculture and Forestry, University of Helsinki) for his help in deposition of Chaetomium globosum strain in HAMBI, the culture collection of Department of Food and Environmental Sciences, Faculty of Agriculture and Forestry, University of Helsinki. Special thanks are extended to all members of Saint
Katherine Protectorate for their unlimited support during this work.

\section{References}

Abd El-Rahim WM, Moawad H. 2010 Testing the performance of small scale bioremediation unit designed for bioremoval/enzymatic biodegradation of textile azo dyes residues. New York Science Journal 3, 77-92.

Abd El-Thalouth I, Kantouch F, Nassar SH, Youssef MA, El-Hennawi HM. 2008 Ecofriendly discharge printing on cotton fabrics using laccase enzyme. Indian Journal of Fibre \& Textile Research 33, $58-65$.

Abdel-Azeem AM. 1991 - Effect of overgrazing on vegetation, microbes and soil in Ismailia-desert habitat. Biological Diversity, Symposium internacional celebrado en Madrid, pp. 241-246.

Abdel-Azeem AM. 2003 - Ecological and taxonomical studies on ascosporeproducing fungi in Egypt. $\mathrm{PhD}$ thesis, Faculty of Science, Suez Canal University, Egypt, p 217.

Abdel-Azeem AM. 2009 - Operation Wallacea in Egypt. I- A preliminary study on 
diversity of fungi in the world heritage site of Saint Katherine, Egypt. Assiut University Journal of Botany 38, 29-54.

Abdel-Azeem AM. 2010 - The history, fungal biodiversity, conservation, and future perspectives for mycology in Egypt. IMA Fungus 1, 123-142.

Abdel-Azeem AM, Ibrahim ME. 2004 Diversity of terrophilous mycobiota of Sinai. Egyptian Journal of Biology 6, 2131.

Abdel-Hafez SII, Moharram AM, Abdel-Sater AM. 2000 - Soil fungi of the New Valley Area, Western Desert, Egypt. Bulletin Faculty of Science, Assiut University 29, 255-271.

Abdel-Moneim NM, El-Ashry EH, AbdelAzeem AM, Ali AN. 2010 - Marinederived fungi isolated from invertebrates and seaweeds of Mediterranean coast at Alexandria as a source of bioactive secondary metabolites. The first international conference on basic and applied mycology, 9-11 March 2010, Assiut, Egypt, Abstract book, 55-56.

Abdel-Moneim TS, Abdel-Azeem AM. 2009 Operation Wallacea in Egypt. II- Diversity of arbuscular mycorrhizal fungi in different elevation wadis in Saint Katherine Protectorate, Egypt. Assiut University Journal of Botany 38, 55-74.

Abdel-Raheem AM. 1997- Laccase activity of lignicolous aquatic hyphomycetes isolated from the River Nile in Egypt. Mycopathologia 139,145-150.

Abdel-Sater MA. 1990 - Studies on the mycoflora of the New Valley area, Western Desert, Egypt. PhD Thesis, Faculty of Science, Assiut University, Egypt.

Abedin RMA. 2008 - Decolorization and biodegradation of crystal violet and malachite green by Fusarium solani (Marius) Saccardo. A comparative study on biosorption of dyes by the dead fungal biomass. American-Eurasian Journal of Agriculture and Environmental Sciences 1, 17-31.

Abou-Okeil A, El-Shafie A, El Zawahry MM. 2010 - Ecofriendly laccase-hydrogen peroxide/ultrasound-assisted bleaching of linen fabrics and its influence on dyeing efficiency. Ultrason Sonochem 17, 383390.

Anastasi A, Coppola T, Prigione V, Varese G. 2009 - Pyrene degradation and detoxification in soil by a consortium of basidiomycetes isolated from compost: role of laccases and peroxidases. Journal of Hazardous Materials 165, 1229-1233.

Atalla MM, Kheiralla ZH, Hamed ER, Youssry AA, Abd El Aty AA. 2010 - Screening of some marine-derived fungal isolates for lignin degrading enzymes (LDEs) production. Agriculture and Biology Journal of North America 1, 591-599.

Atlas R. 2004 - Handbook of Microbiological Media, CRC Press, New York.

Baldrian P. 2006 - Fungal laccases: occurrence and properties. FEMS Microbiology Reviews 30, 215-242.

Beloqui A, Pita M, Polaina J, Martinez-Arias A, Golyshina OV, Zumarraga M, Yakimov MM, García-Arellano H, Alcalde M, Fernández VM, Elborough K, Andreu JM, Ballesteros A, Plou FJ, Timmis KN, Ferrer M, Golyshin PN. 2006- Novel polyphenol oxidase mined from a metagenome expression library of bovine rumen: biochemical properties, structural analysis and phylogenetic relationship. Journal of Biological Chemistry 281, 22933-22942.

Bertrand MG. 1895 - Sur la laccase et sur le pouvoir oxydant de cette diastase. Les Comptes rendus de l'Académie des Sciences (Paris) 12, 266-269.

Bollag JM, Shuttleworth KL, Anderson DH. 1988 - Laccase-mediated detoxification of phenolic compounds. Applied and Environmental Microbiology 54, 30863091.

Booth C. 1971 - The genus Fusarium. Kew, Commonwealth Mycological Institute.

Bourbonnais R, Paice MG, Freiermuth B, Bodie E, Borneman S. 1997- Reactivities of various mediators and laccase with kraft pulp and lignin model compounds. Applied and Environmental Microbiology 63, 4627-4632.

Camarero S, García O, Vidal T, Colom J, del Río JC, Gutiérrez A, Gras J, Monje R, Martínez MJ, Martínez ÁT. 2004 Efficient bleaching of non-wood highquality paper pulp using laccase-mediator 
system. Enzyme and Microbial Technology 35, 113-120.

Cannon PF. 1986 - A revision of Achaetomium, Achaetomiella and Subramaniula, and some similar species of Chaetomium. Transactions of the British Mycological Society 87, 45-76.

Chandra RP, Ragauskas AJ. 2002 - Evaluating laccase-facilitated coupling of phenolic acids to high-yield kraft pulps. Enzyme and Microbial Technology 30, 855-861.

Claus H. 2004 - Laccases: structure, reactions, distribution. Micron 35, 93-96.

Coll PM, Abalos JMF, Villanueva JR, Santamaria R, Perez P. 1993 - Purification and characterization of a phenoloxidase (laccase) from the lignin-degrading basidiomycete PM1 (CECT 2971). Applied and Environmental Microbiology 59, 2607-2613.

Couto SR, Herrera JLT. 2006 - Industrial and biotechnological applications of laccases: a review. Biotechnology Advances 24, 500513.

Domsch KH, Gams W, Anderson TH. 2007Compendium of Soil Fungi. IHW-Verlag, Eching.

D'Souza DT, Verma AK, Mathew M, Raghukumar C. 2006a - Effect of nutrient nitrogen on laccase production, its isozyme pattern and effluent decolorization by a fungus isolated from mangrove wood. Indian Journal of Marine Science 35, 364372.

D'Souza DT, Tiwari R, Sah AK, Raghukumar C. 2006b - Enhanced production of laccase by a marine fungus during treatment of colored effluents and synthetic dyes. Enzyme and Microbial Technology 38, 504-511.

Edens WA, Goins TQ, Dooley D, Henson JM. 1999 - Purification and characterization of a secreted laccase of Gaeumannomyces graminis var. tritici. Applied and Environmental Microbiology 65, 30713074.

Eggert C, Temp U, Dean JFD, Eriksson KEL. 1995 - Laccase mediated formation of the phenoxazinone derivative, cinnabarinic acid. FEBS Letters 376, 202-206.

El Fallal AA. 2001 - Decolourization of the dye Poly R- 478 and oxidation of some phenols by some Basidiomycetes. Bulletin of Faculty of Science, Assiut University 30, 271-283.

El-Fakharany EM, Haroun BM, $\mathrm{Ng} \mathrm{TB}$, Redwan ER. 2010 - Oyster mushroom laccase inhibits hepatitis $C$ virus entry into peripheral blood cells and hepatoma cells. Protein and Peptide Letters 17, 1031-1039.

El-Fallal AA, El-Diasty GG. 2006 - Evaluation of Egyptian white-rot fungi for their ability to produce ligninolytic enzymes and decolorization of Poly R-478. Bulletin of Faculty of Science Elmenia University 17, 1-44.

Ellis MB. 1971- Dematiaceous Hyphomycetes. Kew, Surrey, England, Commonwealth Mycological Institute.

Ellis MB. 1976 - More dematiaceous Hyphomycetes. Kew, Surrey, England, Commonwealth Mycological Institute.

El-Shora HM, Youssef MM, Khalaf SA. 2008 - Inducers and inhibitors of laccase from Penicillium. Biotechnology 7, 35-42.

El-Zayat SA. 2008 - Preliminary studies on laccase production by Chaetomium globosum and endophytic fungus in Glinus lotoides. American-Eurasian Journal of Agriculture and Environmental Sciences 3, 86-90.

Fisher PJ, Petrini O, Sutton BE. 1993 - A comparative study of fungal endophytes in leaves, xylem and bark of Eucalyptus in Australia and England. Sydowia 45, 338345.

Galhaup C, Wagner H, Hinterstoisser B, Haltrich D. 2002 - Increased production of laccase by the wood-degrading basidiomycete Trametes pubescens. Enzyme and Microbial Technology 30, 529-536.

Garrett SD. 1981- Soil Fungi and Soil Fertility. 2nd edn. Pergamon Press, Oxford.

Ghindilis AL. 2000 - Direct electron transfer catalysed by enzymes: application for biosensor development. Biochemical Society Transactions 28, 84-89.

Gomaa OM. 2005 - Improving phenol red decolourization using laccase-mediator system. International Journal of Agriculture and Biology 7, 25-29.

Gomaa OM, Linz EJ, Reddy CA. 2008Decolorization of victoria blue by the 
white rot fungus, Phanerochaete chrysosporium. World Journal of Microbiology and Biotechnology 24, 2349-2356.

Gomaa OM, Momtaz OA, Abd El Kareem H, Fathy R. 2011 - Isolation, identification, and biochemical characterization of a brown rot fungus capable of textile dye decolorization. World Journal of Microbiology and Biotechnology 27, 1641-1648.

Hatakka A. 2001 - Biodegradation of lignin. In: Lignin, Humic Substances and Coal, M. Hofrichter, A. Steinbuchel, Eds., pp. 129-179,

Wiley-VCH,Weinheim, Germany.

Hattori M, Konishi H, Tamura Y, Konno K, Sogawa K. 2005 - Laccase-type phenoloxidase in salivary glands and watery saliva of the green rice leafhopper, Nephotettix cincticeps. Journal of Insect Physiology 51, 1359-1365.

Hawksworth DL. 2001 - The magnitude of fungal diversity: the 1.5 million species estimate revisited. Mycological Research 105, 1422-1432.

Jordaan J, Leukes WD. 2003 - Isolation of a thermostable laccase with DMAB and MBTH oxidative coupling activity from a mesophilic white-rot fungus. Enzyme and Microbial Technology 33, 212-219.

Kar S, Mandal A, Mohapatra PK, Mondal KC, Pati BR. 2006 - Production of cellulasefree xylanase by Trichoderma reesei SAF3. Brazilian Journal of Microbiology 37, 462-464.

Kirk, P, Cannon PF, Minter DW, Stalpers JA. 2008 - Ainsworth \& Bisby's Dictionary of the Fungi. 10th edn. CAB International, Wallingford, UK.

Kues U, Liu Y. 2000 - Fruiting body production in basidiomycetes. Applied Microbiology and Biotechnology 54, 141152.

Kunamneni A, Ballesteros A, Plou FJ, Alcalde M. 2007 - Fungal laccase- a versatile enzyme for biotechnological applications. In: Communicating Current Research and Educational Topics and Trends in Applied Microbiology A. Mendez-Vilas, Ed., vol. 1, pp. 233-245, Formex, Badajoz, Spain.
Kunamneni A, Ghazi I, Camarero S, Ballesteros A, Plou FJ, Alcalde M. 2008 Decolorization of synthetic dyes by laccase immobilized on epoxy-activated carriers. Process Biochemistry 43, 169178.

Lande R. 1996 - Statistics and partitioning of species diversity, and similarity among multiple communities. Oikos 76, 5-13.

Leontievsky AA, Vares T, Lankinen P, Shergill JK, Pozdnyakova NN, Myasoedova NM, Kalkkinen N, Golovleva LA, Cammack R, Thurston CF, Hatakka A. 1997 - Blue and yellow laccases of ligninolytic fungi. FEMS Microbiology Letters 156, 9-14.

Lund M, Ragauskas AJ. 2001 - Enzymatic modification of kraft lignin through oxidative coupling with water-soluble phenols. Applied Microbiology and Biotechnology 55, 699-703.

Mendoza L. 2011- Laccases from new fungal sources and new promising applications. Ph.D. thesis, Department of Biotechnology, Lund University, Sweden.

Mikiashvili N, Wasser SP, Nevo E, Elisashvili V. 2006 - Effects of carbon and nitrogen sources on Pleurotus ostreatus ligninolytic enzyme activity. World Journal of Microbiology and Biotechnology 22, 9991002.

Mikolasch A, Schauer F. 2009 - Fungal laccases as tools for the synthesis of new hybrid molecules and biomaterials. Applied Microbiology and Biotechnology 82, 605-624.

Minussi RC, Miranda MA, Silva JA, Ferreira $\mathrm{CV}$, Aoyama H, Marangoni S, Rotilio D, Pastore GM, Duran N. 2007 Purification, characterization and application of laccase from Trametes versicolor for colour and phenolic removal of olive mill wastewater in the presence of 1-hidroxybenzotriazole. African Journal of Biotechnology 6, 1248-1254.

Minussi RC, Pastore GM, Durán N. 2002Potential applications of laccase in the food industry. Trends in Food Science and Technology 13, 205-216.

Moubasher AH, Abdel-Hafez SII, ElMaghraby OMO. 1985 - Studies on soil mycoflora of Wadi Bir- El- Ain, Eastern 
Desert, Egypt. Cryptogamie Mycologie 6, 129-143.

Moussa TA. 2009 - Molecular characterization of the phenol oxidase (pox2) gene from the ligninolytic fungus Pleurotus ostreatus. FEMS Microbiology Letters 298, 131142.

Moussa TA. 2011 - Cloning and sequencing of phenol oxidase 1 (pox1) gene from Pleurotus ostreatus. African Journal of Biotechnology 10, 1299-1308.

Niku-Paavola ML, Fagerström R, Kruus K, Viikari L. 2004 - Thermostable laccases produced by a white-rot fungus from Peniophora species. Enzyme and Microbial Technology 35, 100-102.

Nishizawa Y, Nakabayashi K, Shinagawa E. 1995 - Purification and characterization of laccase from white rot fungus Trametes sanguinea M85-2. Journal of Fermentation and Bioengineering 80, 91-93.

Nyanhongo GS, Gomes J, Gubitz G, Zvauya R, Read JS, Steiner W. 2002 - Production of laccase by a newly isolated strain of Trametes modesta. Bioresource Technology 84, 259-263.

Ohga S, Royse DJ. 2001 - Transcriptional regulation of laccase and cellulase genes during growth and fruiting of Lentinula edodes on supplemented sawdust. FEMS Microbiology Letters 201, 111-115.

Okino LK, Machado KMG, Fabric C, Bonomi VLR. 2000 - Ligninolytic activity of tropical rainforest basidiomycetes. World Journal of Microbiology and Biotechnology 16, 889-893.

Pitt JI. 1980 - The Genus Penicillium and its teleomorphic states Eupenicillium and Talaromyces. London, Academic Press. p. 634.

Ponzoni C, Beneventi E, Cramarosaa MR, Raimondi S, Trevisi G, Pagnoni UM, Riva S, Forti L. 2007 - Laccase-catalyzed dimerization of hydroxystilbenes. Advanced Synthesis and Catalysis 349, 1497-1506.

Pukahutal C, Suwanarit P, Shianagawa E, Hoshida H, Nishizawa Y. 2004 Combination of laccase, xylanase and cellulase in lignocellulose degradation by white rot fungi, Lentinus polychrous Lev. and L. squarrosulus Mont. Kasetsart Journal (Natural Science) 38, 65-73.

Punnapayak H, Koohirun M, Liawsakul P. 2002 - Biological Bleaching of Paper Pulps. Research report submitted to National Research Council of Thailand. p. 115.

Raper KB, Fennell DI. 1965 - The Genus Aspergillus. Williams \& Wilkins, Baltimore, USA. P. 686.

Raper KB, Thom CA. 1949 - A Manual of the Penicillia. Williams \& Wilkins, Baltimore, USA.

Rodríguez S, Toca JL. 2006 - Industrial and biotechnological applications of laccases: a review. Biotechnology Advances 24, 500513.

Selinheimo E, Kruus K, Buchert J, Hopia A, Autio K. 2006 - Effects of laccase, xylanase and their combination on the rheological properties of wheat doughs. Journal of Cereal Science 43, 152-159.

Shraddha RS, Sehgal S, Kamthania M, Kumar A. 2011 - Laccase: microbial sources, production, purification, and potential biotechnological applications. Enzyme Research: Article ID 217861, 11 pages doi: $10.4061 / 2011 / 217861$.

Thurston CF. 1994 - The structure and function of fungal laccases. Microbiology 140, 19-26.

Varnaitè R, Raudonienè V, Bridžiuvienè D. 2011- Enzymatic biodegradation of lignincellulose complex in plant origin material. Materials Science (Medžiagotyra) 17, 99103.

Vikineswary S, Abdullah N, Renuvathani M, Sekaran M, Pandey A, Jones GEB. 2006 Productivity of laccase in solid substrate fermentation of selected agro-residues by Pycnoporus sanguineus. Bioresource Technology 97, 171-177.

Viswanath B, Chandra MS, Pallavi H, Reddy BR. 2008 - Screening and assessment of laccase producing fungi isolated from different environmental samples. African Journal of Biotechnology 7, 1129-1133.

von Arx JA. 1981 - The Genera of Fungi Sporulating in Pure Culture, 3rd edn. J. Cramer, Vaduz. 424 p.

von Arx JA, Guarro J, Figueras MJ. 1986 - 
The ascomycete genus Chaetomium. Beihefte zur Nova Hedwigia 84, 1-162.

Wang JW, Wu JH, Huang WY, Tan RX. 2006 -Laccase production by Monotospora sp., an endophytic fungus in Cynodon dactylon. Bioresource Technology 97, 786-789.

Watanabe T. 2002 - Pictorial Atlas of Soil and Seed Fungi. Morphologies of Cultured Fungi and Key to Species, 2nd edn. CRC Press, Boca Raton.

Wesenberg D, Kyriakides I, Agathos SN. 2003 - White-rot fungi and their enzymes for the treatment of industrial dye effluents. Biotechnology Advances 22, 161-187.

Wood DA. 1980 - Production purification and properties of extracellular laccase of Agaricus bisporous. Journal of General Microbiology 117, 327-338.

$\mathrm{Xu}$ F. 2005 - Applications of oxiredoreductases: recent progress.
Industrial Biotechnology 1, 38-50.

Yehia RSA. 2007 - Production and biological evaluation of laccase from edible mushroom Pleurotus ostreatus. M.Sc. thesis, Botany Department, Faculty of Science, Cairo University, Egypt.

Yoshida H. 1883 - Chemistry of lacquer urushi. Part 1. Journal of the Chemical Society 43, 472-486.

Youn HD, Kim KJ, Maeng JS, Han YH, Jeong IB, Jeong G, Kang SO, Hah YC. 1995 Single electron transfer by an extracellular laccase from the white-rot fungus Pleurotus ostreatus. Microbiology 141, 393-398

Youssef GA, Botros WA, Daba AS. 2008 Screening for enzymatic and biological activity of Pleurotus ostreatus- a popular edible mushroom in Egypt (specialty mushrooms). Mushroom News. 